اثر تيمارهاى كم آبيارى و شورى آب بر واكنشهاى رشدى و عملكردى گندم رقم سيروان

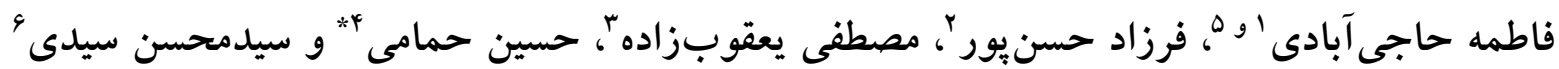

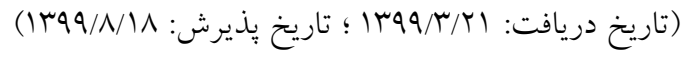

حكيده

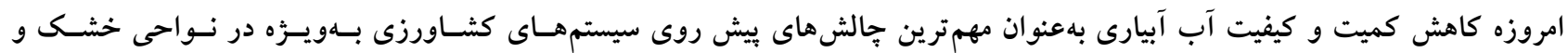

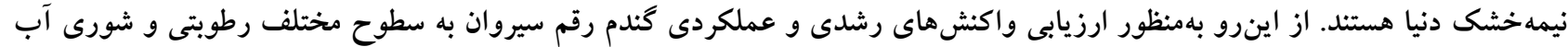

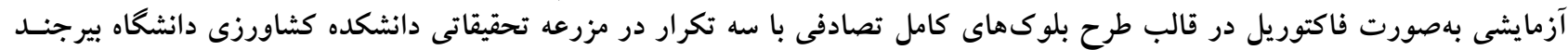

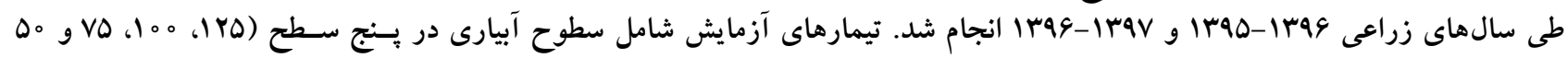

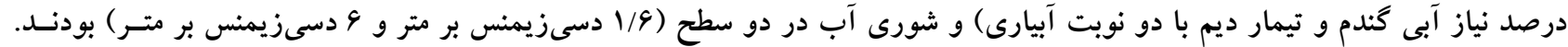

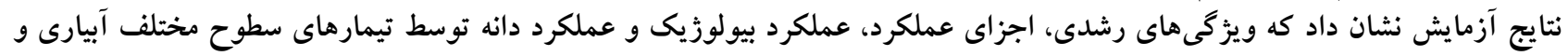

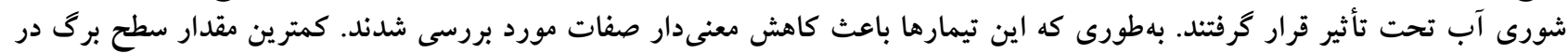

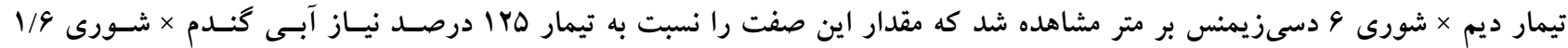

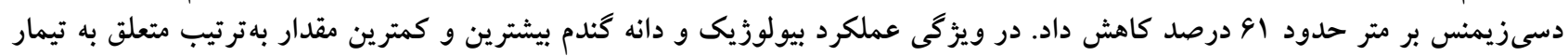

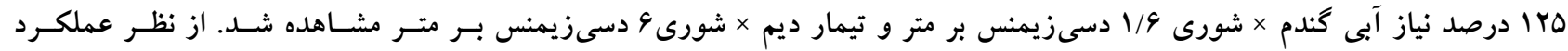

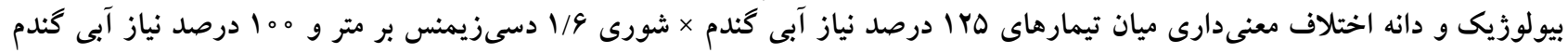

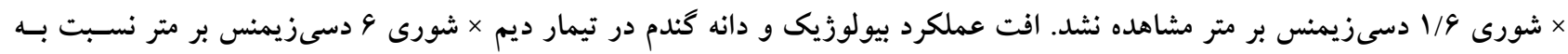

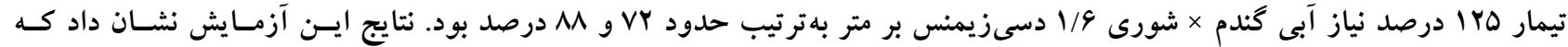

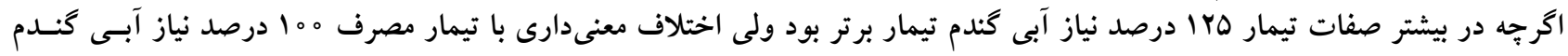

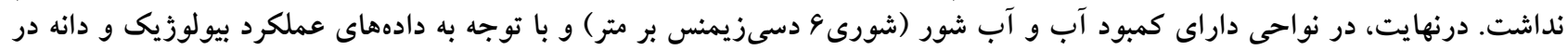

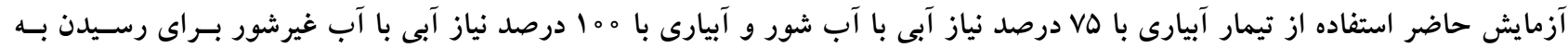

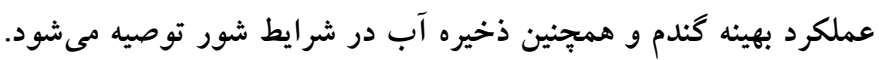

وازههاى كليدى: آب شور ، عملكرد بيولوزيك، عملكرد دانه

او r. به ترتيب دانش آموخته دكترى آبيارى و زهكشى و دانشيار گروه علوم و مهندسى آب، دانشكده آب و خاك، دانشگاه زابل

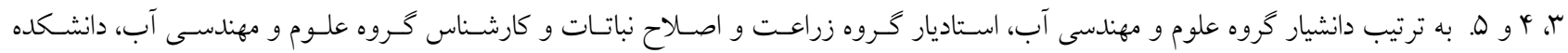
كشاورزى، دانشخاه بير جند 9. محقق مركز تحقيقات و آموزش كشاورزى و منابع طبيعى استان مركزى، سازمان تحقيقات، آموزش و ترويج كشاورزى، اراك، ايران

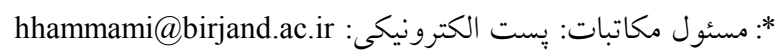


در هر سنبله در نتيجه كاهش آبيارى روى مسىدهـد (ه). نتسايج

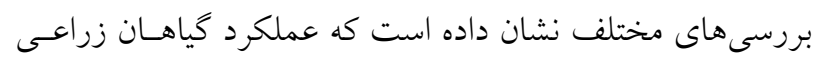

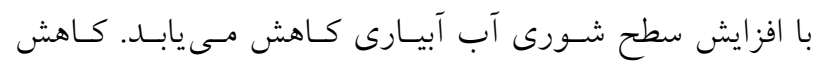

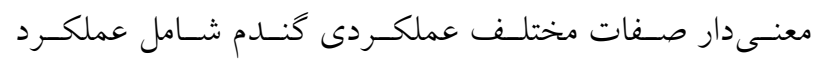

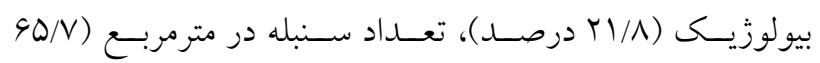

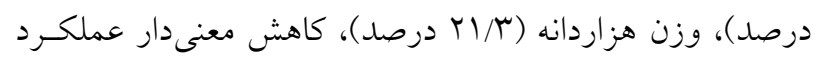

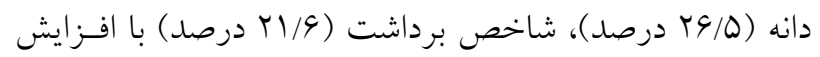

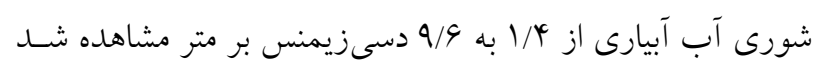

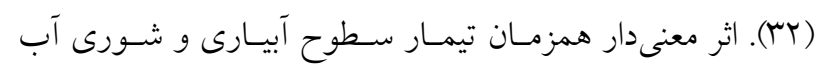

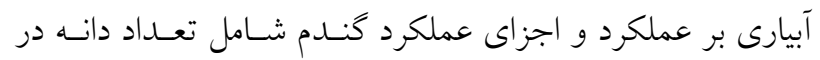
سنبله، عملكرد دانه و شاخص برداشت گزارش شده است (I (I). رقم سيروان با كد WS-85-10 و بـا شـجره (Prl/2*Pastor) در سال سيץ|

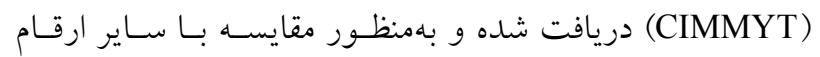

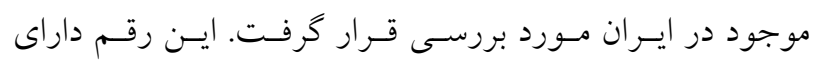

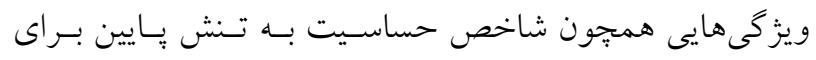

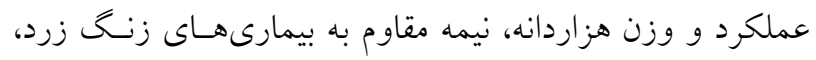

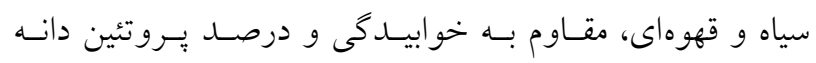

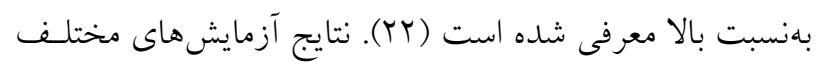

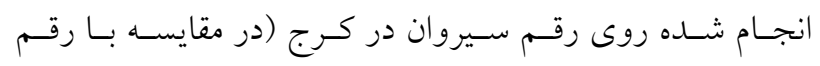

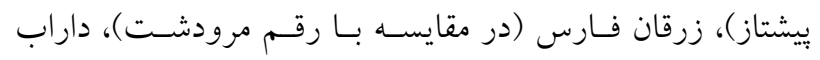

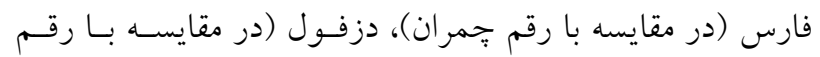

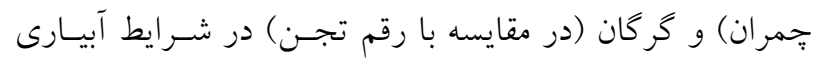

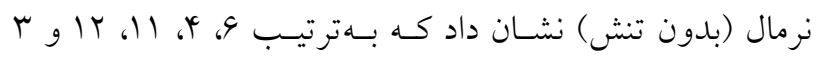

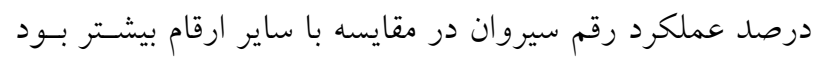

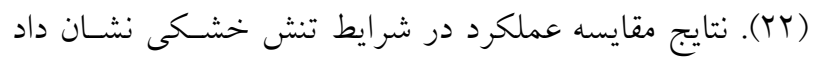
كه شاخص حساسيت به تنش خشكى بــراى رقـم سـيروان بود كه در مقايسه با اغلب ارقام مورد مطالعه اين شاخص كمتـر بود كه نشاندهنده تحمل بيشتر اين رقم به خشكى اسـت (YY).

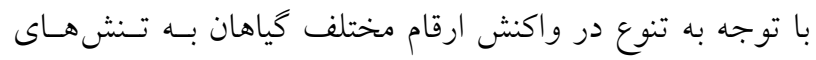
خشكى و شورى بررسى واكنش ارقام مختلف به ايـن تـنشهـا

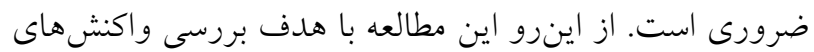

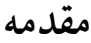

كُندم (Triticum aestivum L.) يكى از اولين گياهانى است كـه. توسط اجداد انسان بهطور وسيع و كستردهاى در مناطق مختلف

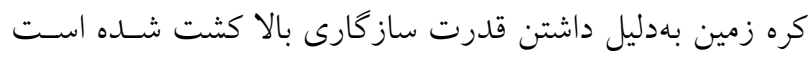
Y०IV (YN)

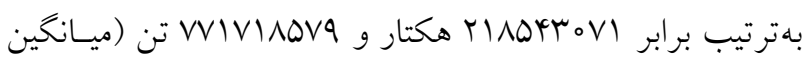

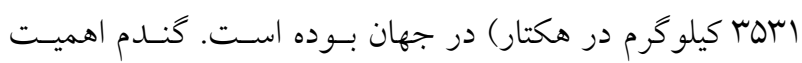

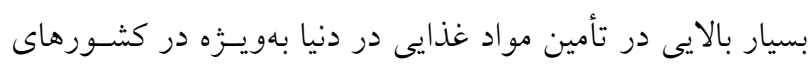

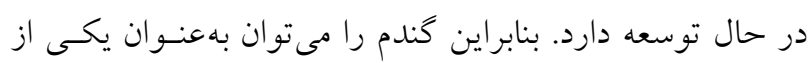

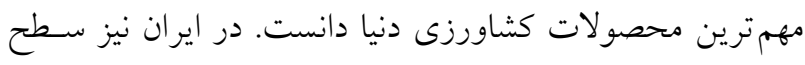

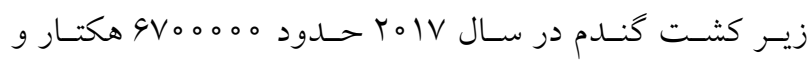

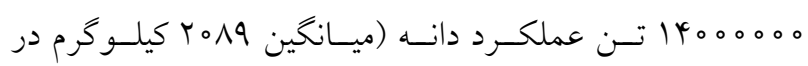
هكتار) گزارش شده است (V)

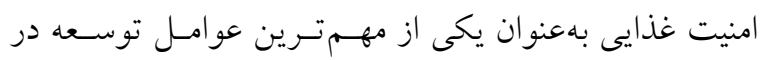

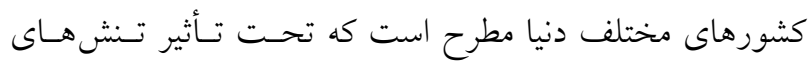

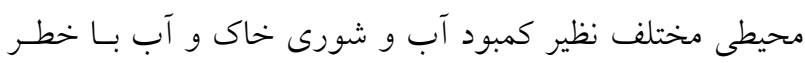

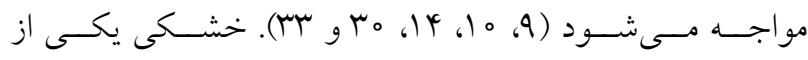
مهم ترين تنش هاى محيطى است كه رشـــ و نمـو كياهـان را از

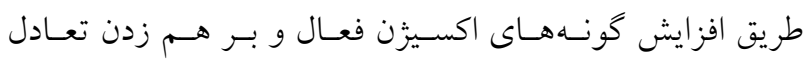

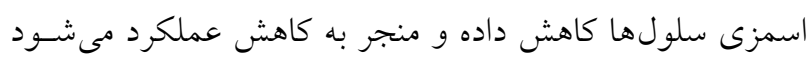

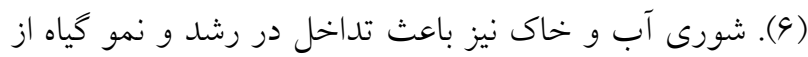

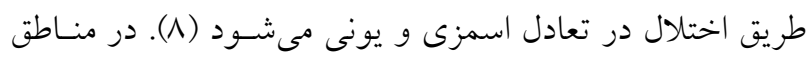

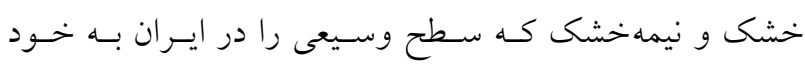

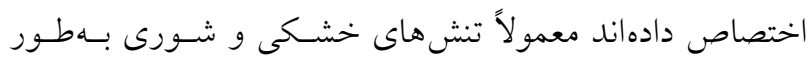
همزمان بروز مىيابند.

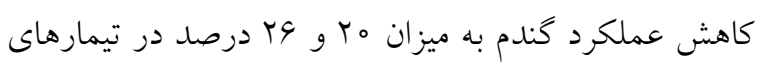
90 و هب درصد آبيارى كامل كزارش شده است كـه البتـه بيـان

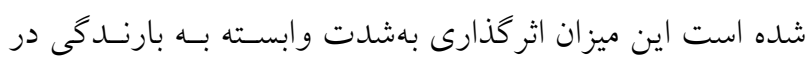

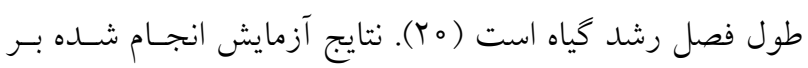

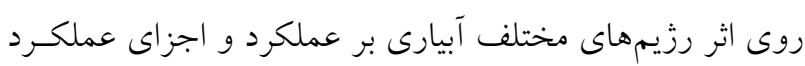

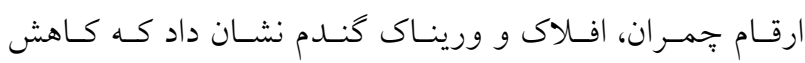
معنى دار وزن هزاردانه، تعداد يُنجه در مترمربع، تعداد سنبلكهــا 
براى هر واحد آزمايشى كرت هايى بـه مسـاحت 9 مترمربـع

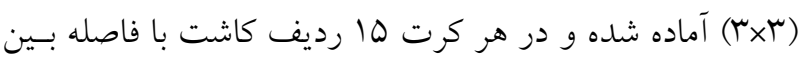

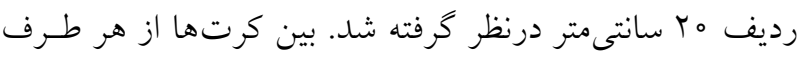

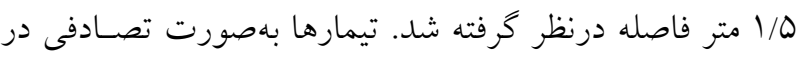

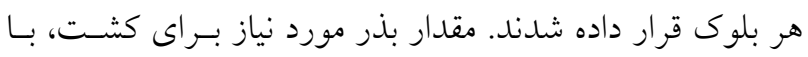

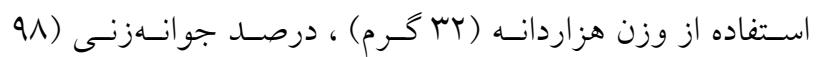
درصد)، ميزان ناخالصى بذرها و ميـزان بـذرهاى شكستهـه شـده

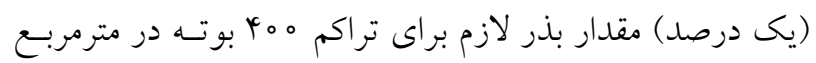
محاسبه شد و سبس براى 9 مترمربـع حسـاب شــده و رو روى 10

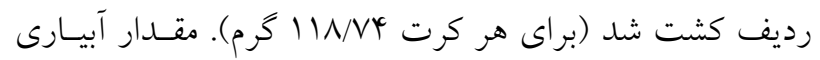
براى هر تيمار با استفاده از كتتورهـاى حجمسى نصـب شــــ در

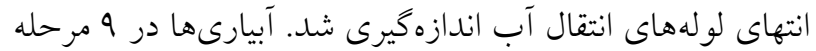

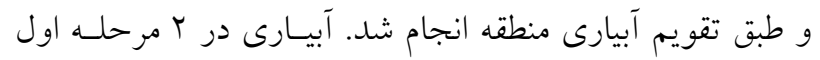

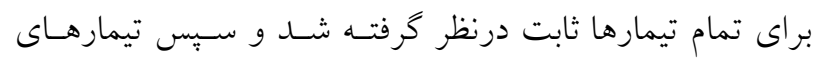

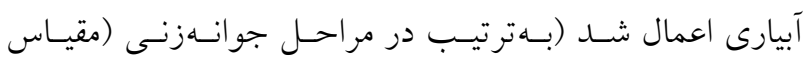

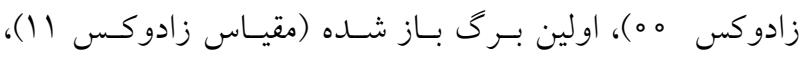

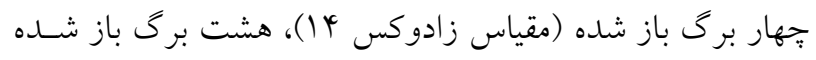

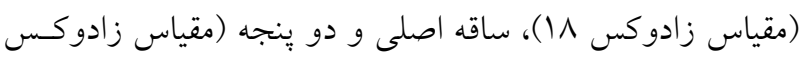

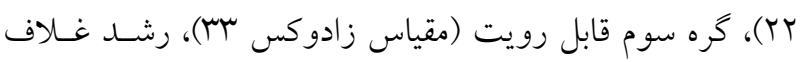

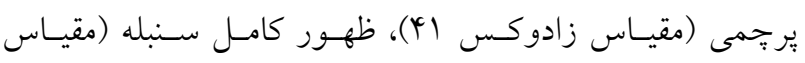

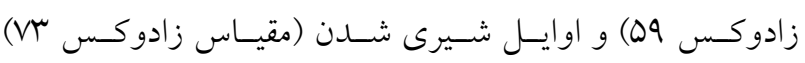

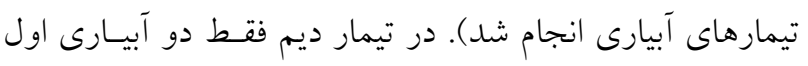

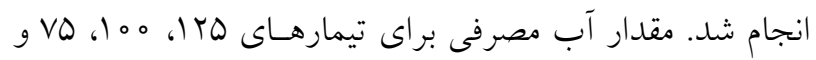

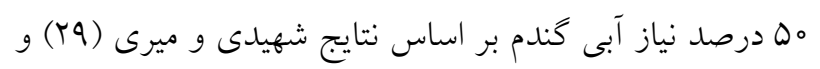

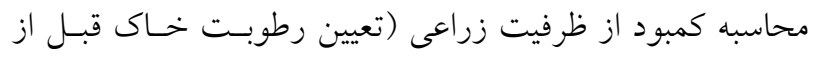

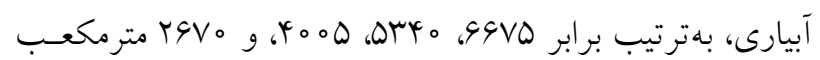

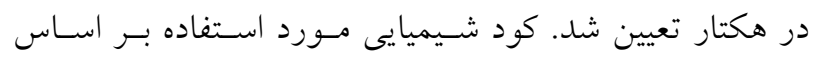

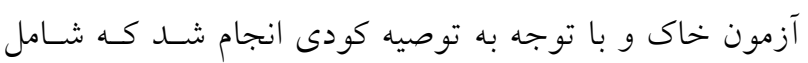

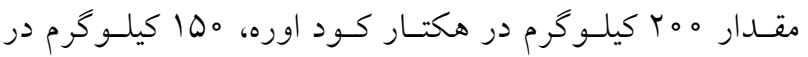

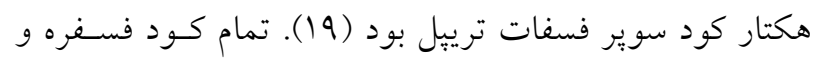
يكسوم كود ازته، قبل از كشـت داخـل شـيارهاى ايجادشــهـ

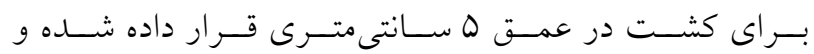

رشدى و عملكردى گندم رقم سيروان در منطقه بيرجند طسى دو

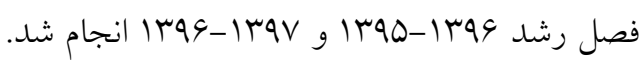

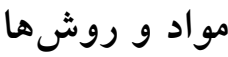

بهمنظور بررسى تأثير تيمارهـاى سـطوح آبيـارى و شـورى آب

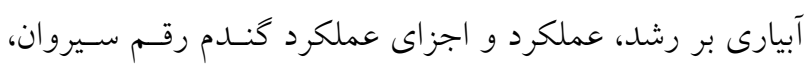

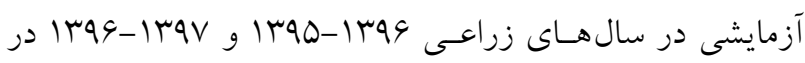

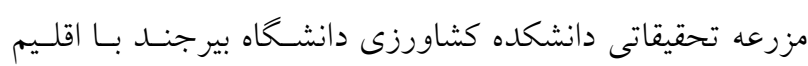

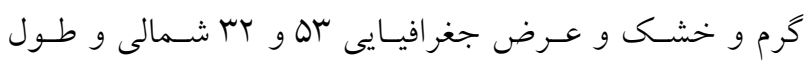

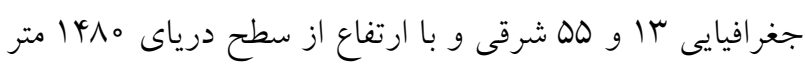
از سطح دريا بهصورت فاكتوريل در قالب طرح بلوكهاى كامل

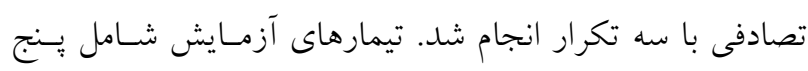

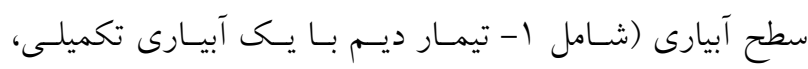

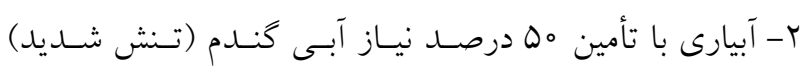

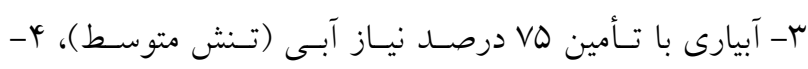

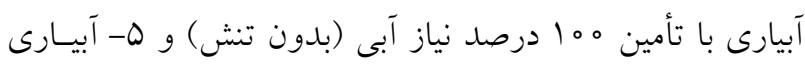

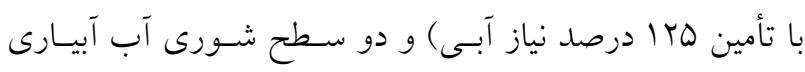

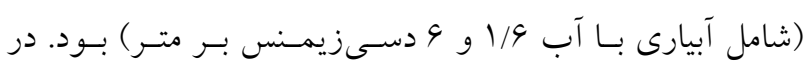
اواخر آبانماه هوسا و وهسا براى آمادهسازى زمين، با كـاوآهن بركرداندار شخم زده شـــ و در مرحلـه بعـــ در اوايسل آذرمـاه

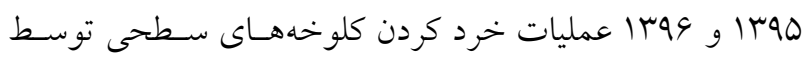
ديسك صورت يذيرفت. يّ از آن به كمك لـولر، كـار تسـطيح

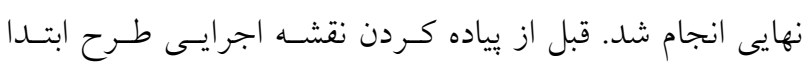

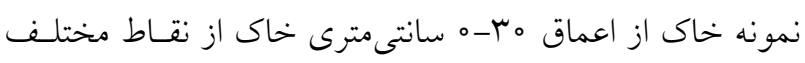

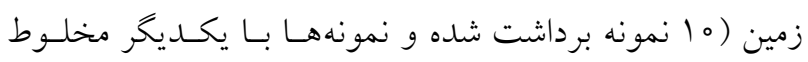

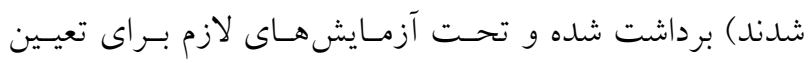

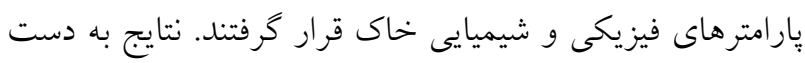

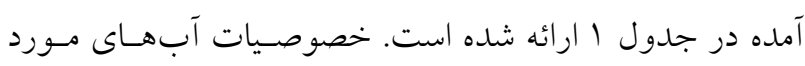
استفاده در آزمايش در جدول ب نشان داده شده أنده است. خصو صيات و يارامترهاى هواشناسى با استفاده از دادههـاى

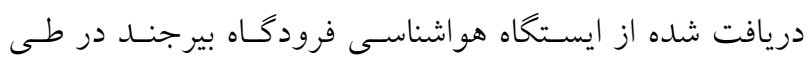
سالهاى آزمايش در جدول ب نشان داده شده است. 
جدول ا. خصوصيات فيزيكى و شيميايى خاك محل آزمايش

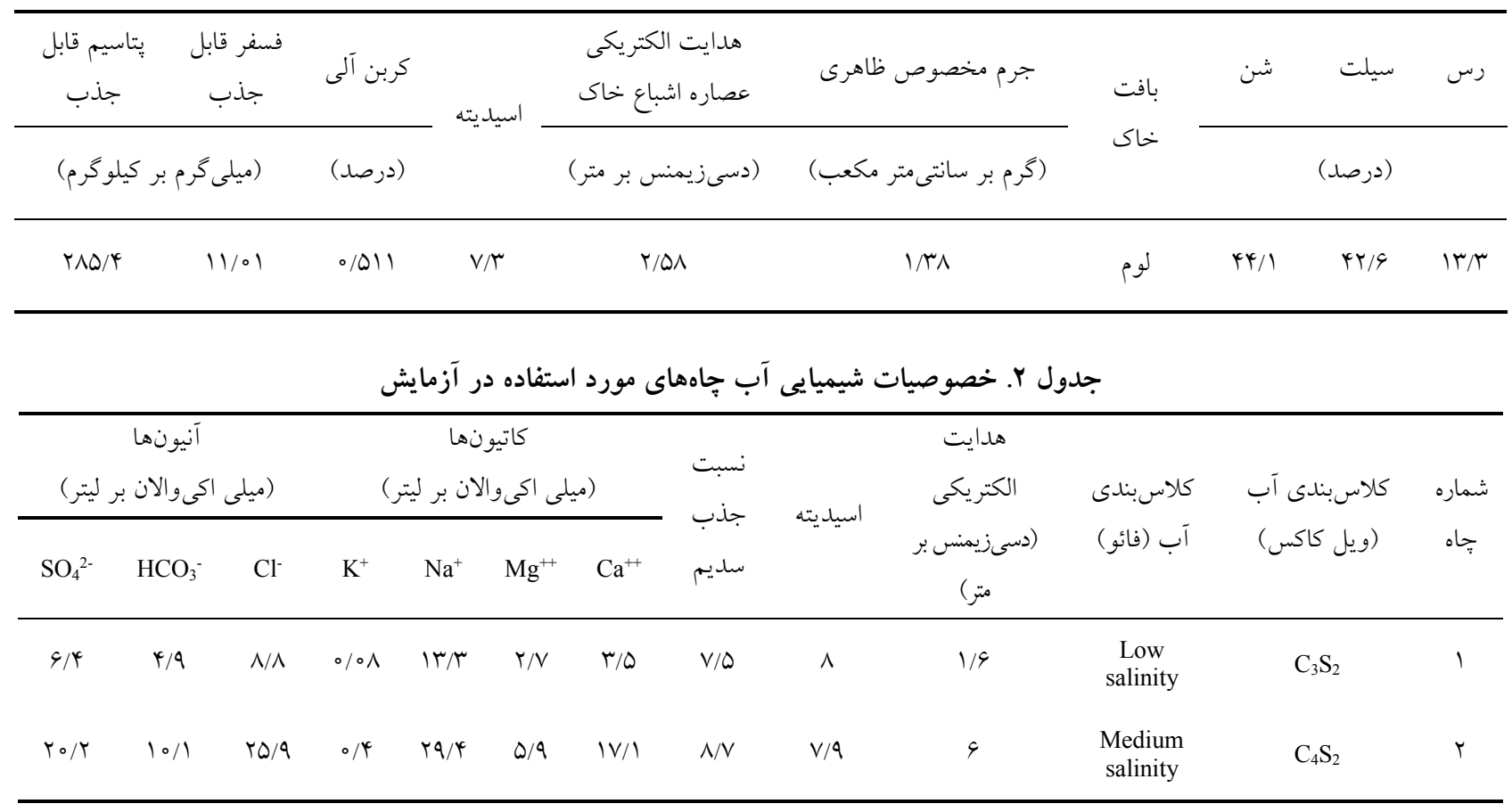

جدول r. آمار هواشناسى در سالهاى اجراى آزمايش

\begin{tabular}{|c|c|c|c|c|c|c|}
\hline (وات بر مترمربع) & $\begin{array}{c}\text { تعداد ساعات آفتابى } \\
\text { (در روزز) }\end{array}$ & 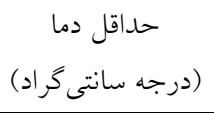 & 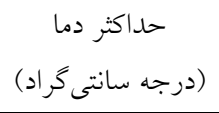 & بارندگى تجمعى ماهانه & سال & ماههاى سال \\
\hline$T Y \& 1 / r$ & $10 / 0 V$ & $10 / \Lambda 0$ & $r 9 / 9 V$ & $\circ$ & 1790 & \multirow[b]{2}{*}{ مهرماه } \\
\hline$T \circ M / D$ & $1 \circ / \pi \Delta$ & $\Lambda / N V$ & TN/9G & $\circ$ & 11499 & \\
\hline$I V V \circ / r$ & $Q / Y Y$ & $4 / 09$ & rm/ & $\circ$ & 1790 & \multirow{2}{*}{ آبانماه } \\
\hline $19 \mathrm{VQ} / \mathrm{V}$ & $9 / \pi \mu$ & $4 / 10$ & $r M / \Delta \Lambda$ & $\circ$ & 1799 & \\
\hline IMYY/Y & $9 / 11$ & r & $10 / Y Y$ & $\varphi / \Lambda$ & $11 \% 90$ & \multirow{2}{*}{ آذرماه } \\
\hline $1490 / V$ & $1 / r q$ & $-Y / V G$ & $14 / N$ & $0 / \mu$ & 1799 & \\
\hline $1 \pi 99 / 4$ & $V / 99$ & $-Y / Y I$ & $14 / \Lambda 9$ & $4 / 0$ & 11490 & \multirow{2}{*}{ دىماه } \\
\hline $11 K r / 1$ & $1 / 1 \circ$ & $-r / 91$ & $19 / 4 \pi$ & $\circ$ & 1599 & \\
\hline 1490 & $0 / 94$ & $1 / 10$ & $\mid r / \Delta \Lambda$ & $\Delta r / q$ & 1790 & \multirow{2}{*}{ ل بهمن ماه } \\
\hline $1194 / 9$ & $9 / 9 T$ & $1 / 10$ & $14 / \mathrm{NA}$ & $\Lambda / r$ & 11499 & \\
\hline$r \mid V Q / r$ & $1 / 91$ & $1 / 9 T$ & IV/RG & $r / 9$ & 1790 & \multirow{2}{*}{ اسفندماه } \\
\hline $1019 / 1$ & $9 / 91$ & Q/VG & $19 / V_{0}$ & $r \Delta / r$ & 11599 & \\
\hline$r \& 4 q / 4$ & $9 / 11$ & $10 M r$ & $T Y / 00$ & $1 V / 9$ & 1799 & \multirow[b]{2}{*}{ فروردينماه } \\
\hline $190 \mathrm{~V} / \mathrm{V}$ & $N / \mu^{\mu}$ & $9 / \pi \Delta$ & $r Q / 1 \circ$ & T\&/V & $1 r 9 V$ & \\
\hline$r q Y 4 / 4$ & $9 / \wedge r$ & $1 T / T G$ & $r \circ / r \Delta$ & 9 & 1799 & \multirow{2}{*}{ رديبهشتماه } \\
\hline$T Y V T / T$ & $9 / 1 r$ & $1 T / V_{0}$ & TV/V。 & $10 / 0$ & $1 r 9 V$ & \\
\hline rGMY/V & $1 Y / D \Lambda$ & $1 N / \circ V$ & $\mathrm{rV} / 0 \mathrm{G}$ & $\circ$ & 11499 & \multirow{2}{*}{ خردادماه } \\
\hline$T V V \circ / D$ & $11 / \Delta \psi^{*}$ & $I V / \Lambda_{0}$ & $r \Delta / 。$ & 。 & 1798 & \\
\hline
\end{tabular}




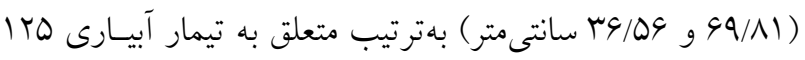

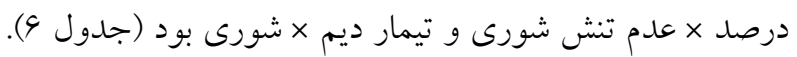

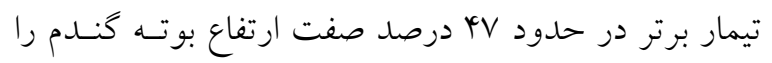

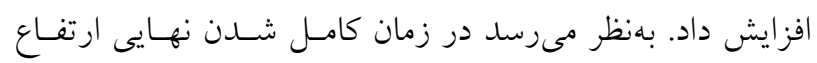

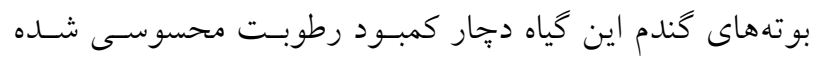
است و بههمين دليل اين عامل سبب كاهش نهايى ارتفـاع بوتسه

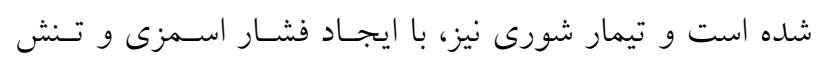

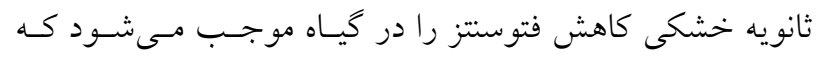

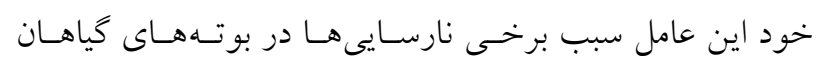

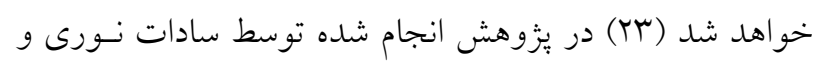

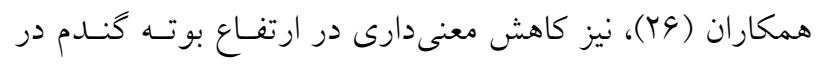
شرايط تنش شورى گزارش شده است.

\section{طول سنبله}

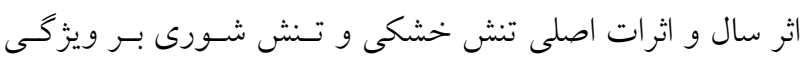

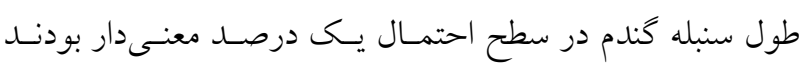

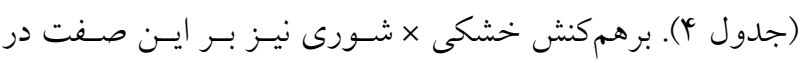

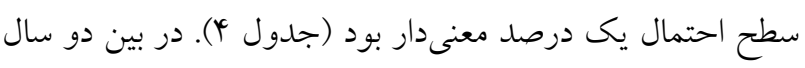

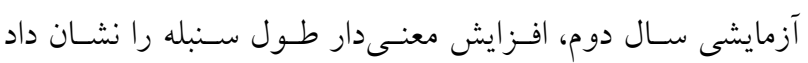
(جدول ه). در بين سطوح خشكى × شورى كمترين طول سـنبله

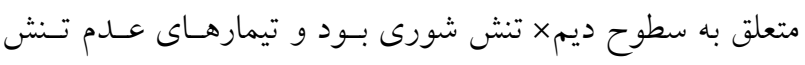

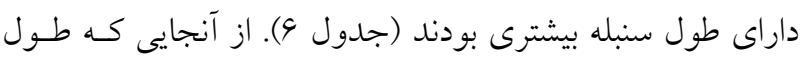

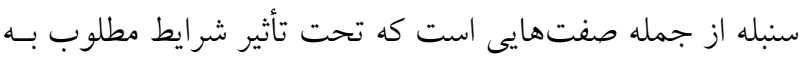

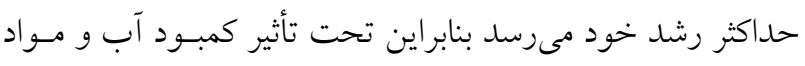

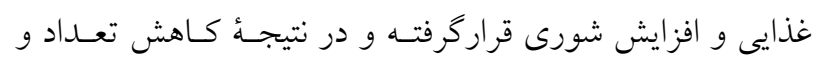

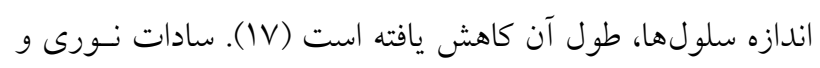

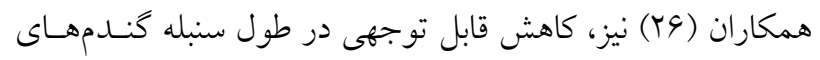
مورد بررسى تحت شرايط تنش را گزارش كردند.

\section{سطح برى} نتايج ميانحين مربعات نشان داد كه اثر سال و اثرات اصلى تسنش خشكى و شورى بر ويزگى سطح برى گندم در سطعح احتمـال

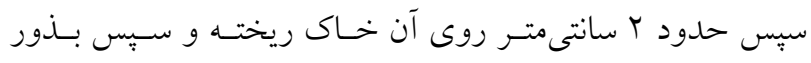

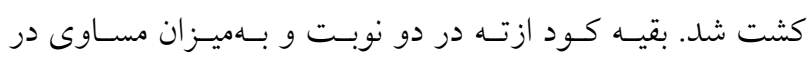

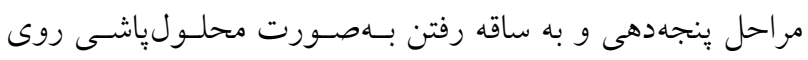

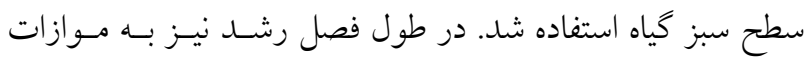

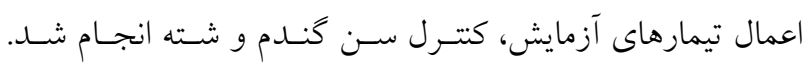

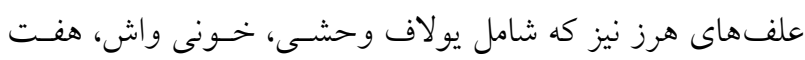

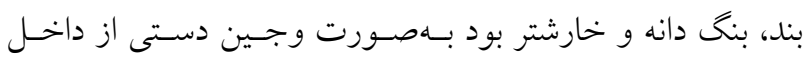

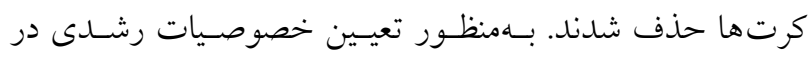

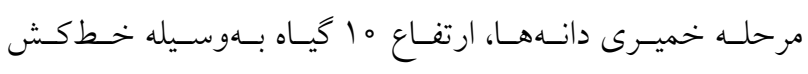

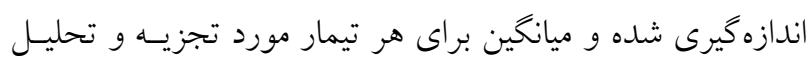

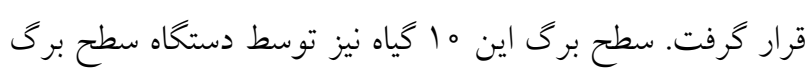
اندازهيرى شد. سبس از بخـش (Delta-T,Windias3, England) مركزى هر كرت نمونه گيرى براى تعيين اجزاى عملكرد، عملكرد

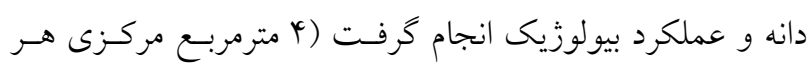

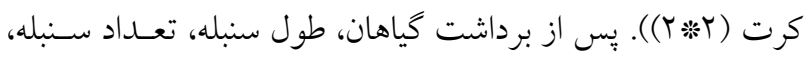

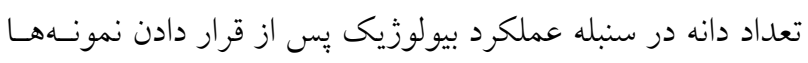

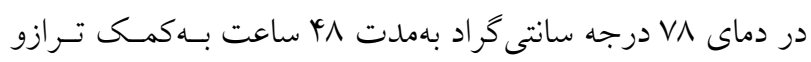

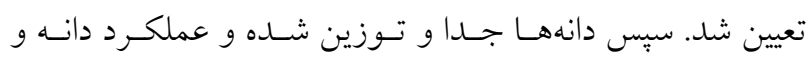

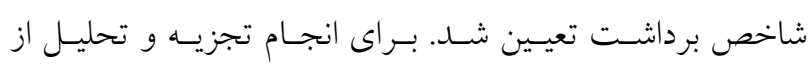

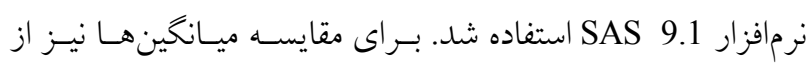
روش LSD محافظت شده استفاده شد.

\section{نتايج و بحث

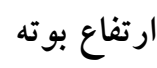

نتايج دادههاى آزمايش نشان داد كه اثر سال بر ارتفاع بوته گندم

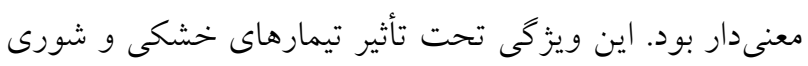

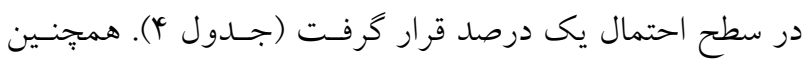

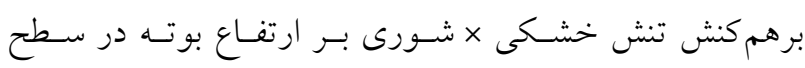

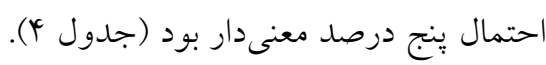

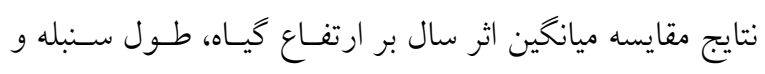

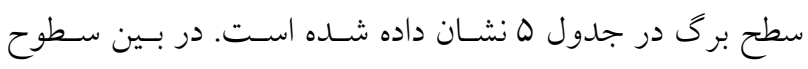
تيمارهاى آزمايشى بيشترين و كمترين ميـزان ارتفـاع بوتـه كنــدم 
جدول f. ميانكين مربعات اثر خشكى و شورى بر برخى ويزٔى هاى رشدى كندم رقم سيروان

\begin{tabular}{|c|c|c|c|c|}
\hline سطح برى & طول سنبله & ارتفاع بوته & درجه آزادى & منبع تغييرات \\
\hline GVIGVGMY $/ \mathrm{Yo}^{* *}$ & $T V / \mu Y^{* *}$ & $\mathrm{~V} / \mathrm{o}^{\mathrm{kns}}$ & 1 & سال \\
\hline VRGTaN/Y。 & $\circ / 10$ & $\circ / 94$ & 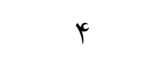 & تكرار × سال \\
\hline $0.0090 \wedge V / 90^{* *}$ & $r V /\left.\Delta\right|^{* *}$ & $\mid$ For $/\left.\Delta\right|^{* *}$ & $r$ & خشكى \\
\hline AVISTrI/No** & $|/ 9|^{* *}$ & $9 \wedge / \mu c^{* *}$ & $r$ & سال × خشكى \\
\hline$|r \mu| 0 \mid 0 \wedge 9 \mu_{0}^{* * *}$ & $\Delta / \Lambda V^{* *}$ & $r q \circ / 9 \mu^{* *}$ & 1 & شورى \\
\hline IrTarrN/r.* & $\circ N r^{*}$ & $19 / 19^{*}$ & $r$ & خشكى × شورى \\
\hline 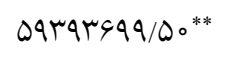 & $\circ / \Delta q^{n s}$ & $0 / 19^{\text {ns }}$ & 1 & سال × شورى \\
\hline $909119 \% / 10^{* * *}$ & $\circ / 1 \circ \mathrm{oss}$ & $10 / v q^{n s}$ & r & سال × خشكى × شورى \\
\hline Frlkt\%o & $0 / r \mu$ & G/VA & rq & خطاى آزمايشى \\
\hline $9 / 9 V$ & $9 / 04$ & $\varphi / \varphi \wedge$ & - & ضريب تغييرات (٪) \\
\hline
\end{tabular}

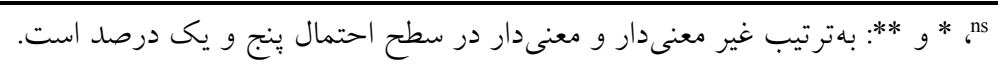

جدول هـ مقايسه ميانخين اثر سال بر برخى ويزگىهاى رشدى گندم رقم سيروان

\begin{tabular}{|c|c|c|c|}
\hline سطح برى (سانتىمتر مربع) & طول سنبله (سانتى متر) & ارتفاع بوته (سانتى متر) & سال \\
\hline$\wedge \triangle 9 V / 10^{\mathrm{b}}$ & $V / r^{b}{ }^{b}$ & $\Delta V / N r^{a}$ & اول اول \\
\hline $109 \Lambda \mu / \gamma_{0} a^{a}$ & $\Lambda / 90^{\mathrm{a}}$ & $\Delta \Lambda / \psi I^{\mathrm{a}}$ & 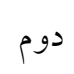 \\
\hline
\end{tabular}

ميانخينهاى هر ستون كه داراى حداقل يك حرف مشترى هستند، بر اساس آزمون LSD اختلاف معنى دارى در سطح ينج درصد ندارند.

جدول 9. مقايسه ميانگين اثر خشكى و شورى بر برخى ويزّى هاى رشدى گندم رقم سيروان

\begin{tabular}{|c|c|c|c|c|}
\hline سطح برى (سانتىمتر مربع) & طول سنبله (سانتىمتر) & ارتفاع بوته (سانتىمتر) & & تيمار \\
\hline $10 \% 40 / \mu^{c}$ & $\Lambda / \wedge \Lambda^{d}$ & $\Delta \wedge / \wedge^{e}$ & عدم شورى & \multirow{2}{*}{ آبيارى هـ } \\
\hline$\Lambda T r q / o^{d}$ & $\Lambda / r \Delta^{\mathrm{d}}$ & $\Delta Q / \circ Q^{f}$ & شورى & \\
\hline $119 \mathrm{FV}^{\mathrm{V}} / \mathrm{I}^{\mathrm{b}}$ & $\Lambda / 9 \Lambda^{\mathrm{abc}}$ & $99 / 1 V^{b}$ & عدم شورى & \multirow{2}{*}{ VQ آبيارى VQ } \\
\hline$\Lambda \Pi \Pi / / \Lambda_{0} d$ & $\Lambda / 4 \gamma^{c d}$ & $9 \circ / \Lambda_{0} \mathrm{de}$ & شورى & \\
\hline $110 Y \Lambda / /^{\mathrm{bc}}$ & $9 / 4 \Delta^{a}$ & $90 / 94 b$ & عدم شورى & \multirow{2}{*}{ آبيارى ه 10} \\
\hline$\Lambda \Delta G 4 / q^{d}$ & $\Lambda / \Lambda \Lambda^{\mathrm{bc}}$ & $q \mu / \Lambda \Lambda^{b c}$ & 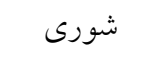 & \\
\hline$|\psi \circ 4| /\left.\right|^{a}$ & $9 / r Y a b$ & $99 / 11^{a}$ & عدم شورى & \multirow{2}{*}{ آبيارى ITD } \\
\hline $10419 / 0^{c}$ & $\Lambda / \Delta \varphi^{\mathrm{cd}}$ & $91 / \sqrt{ } q^{\mathrm{cd}}$ & شورى & \\
\hline VGro/Ad & $\Delta / \Delta H^{\mathrm{e}}$ & GT/MTg & عدم شورى & \multirow{2}{*}{ ديم } \\
\hline$\Delta H \circ Q / /^{\circ}$ & $\varphi / \mu^{f f}$ & $\mathrm{r} / 0 / 09^{\mathrm{h}}$ & شورى & \\
\hline
\end{tabular}

ميانكين هاى هر ستون كه داراى حداقل يك حرف مشترى هستند، بر اساس آزمون LSD اختلاف معنى دارى در سطح ينج درصد ندارند. 
مترمربع است (جدول 9). از مهم ترين نتايج و مضرات تنشهاى

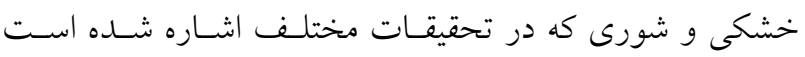

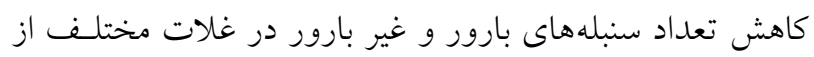

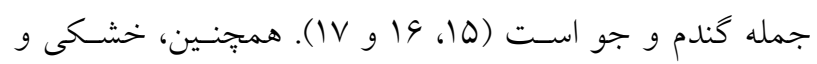
شورى بهطور بارزى سبب كاهش تعداد دانه در سنبلهاى بارور

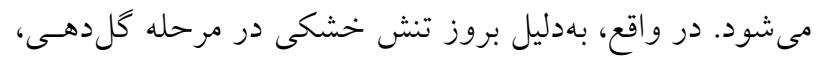

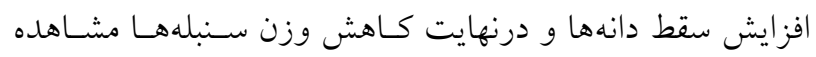

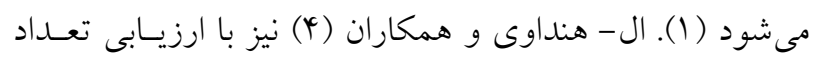

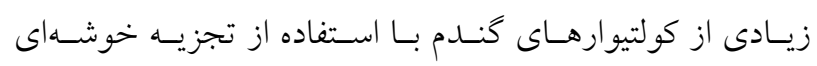

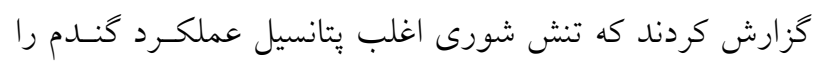

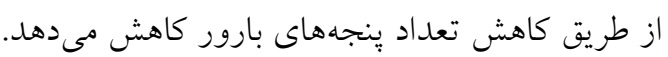

\section{تعداد دانه در سنبله}

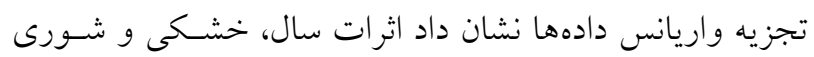

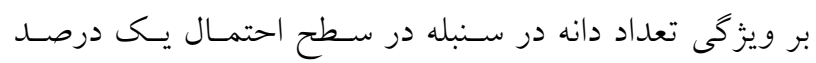

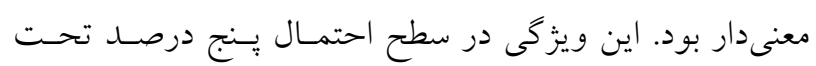

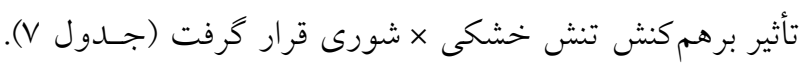

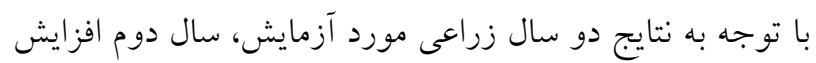

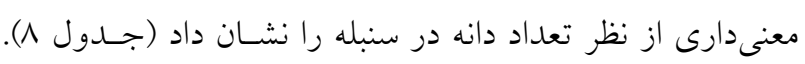

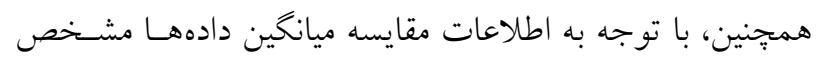

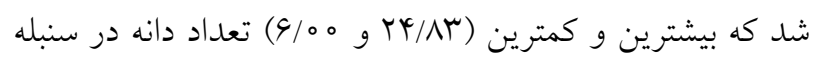

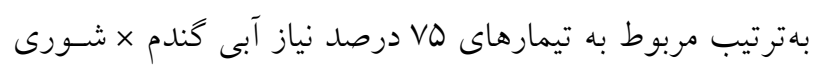

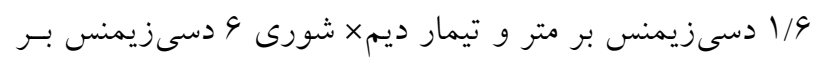
متر تعلق گرفت (جدول 9).

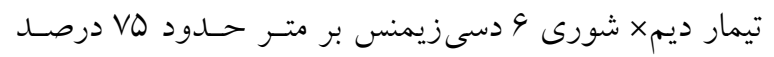

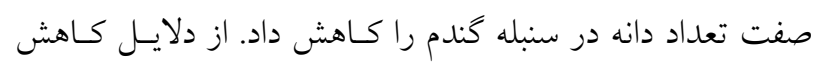

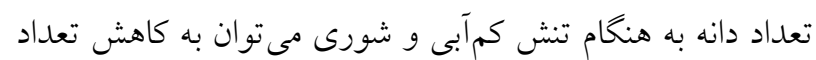

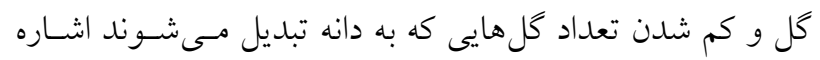

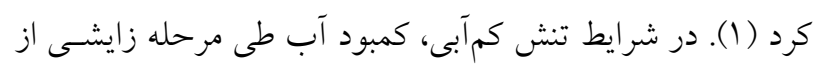

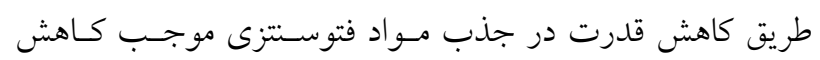

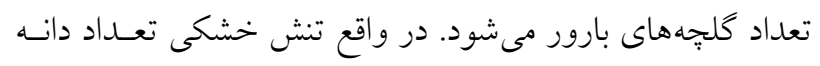

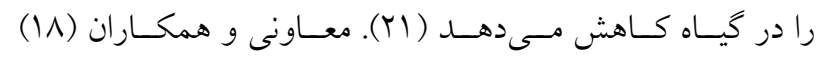

يك درصد معنى دار بودند و برهم كنش تنش خشـكى × شـورى

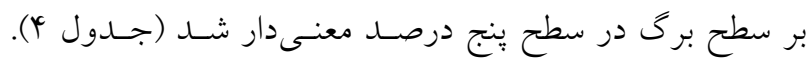

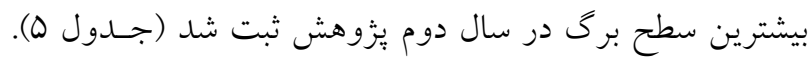

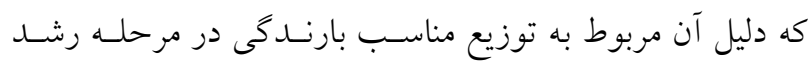

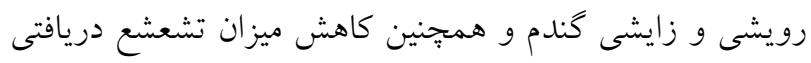
در واحد سطح و درنتيجه كاهش تبخيـر و تعـرق در سـال دوم

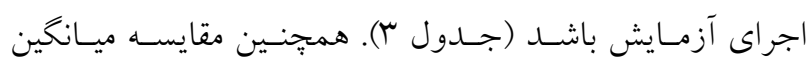

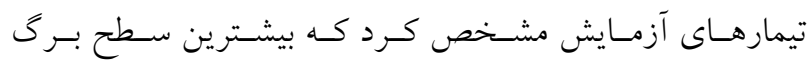

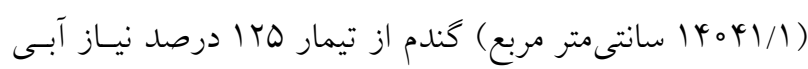

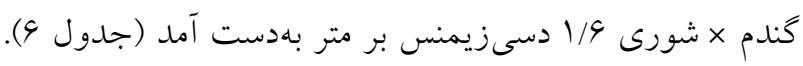

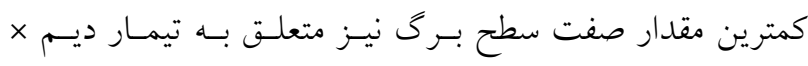

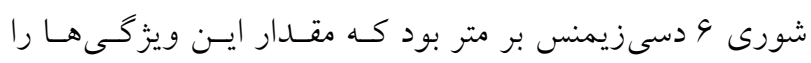

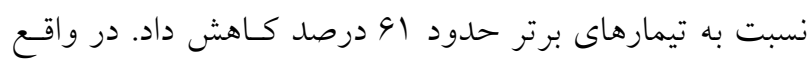

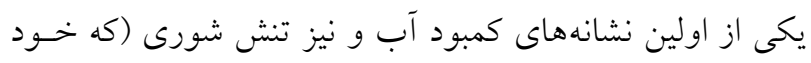

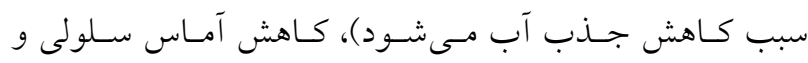

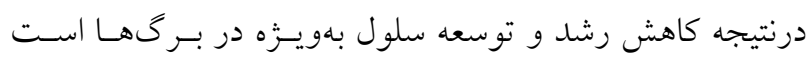

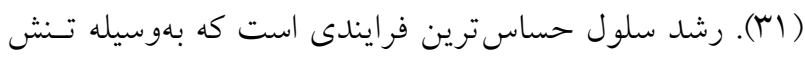

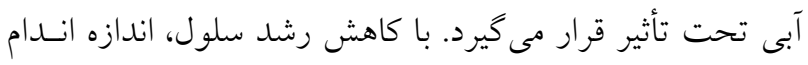

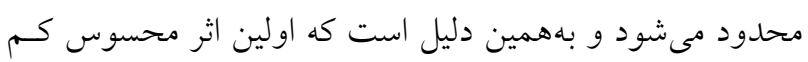

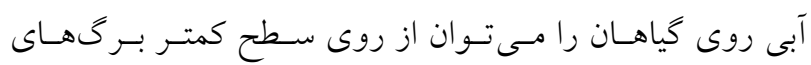
كياهان تشخيص داد (1) (1). (1)

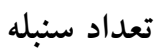

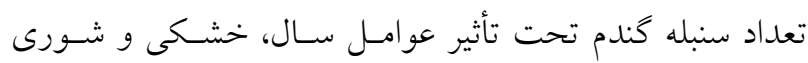
قراركرفته و برهم كنش خشكى و شورى نيـز در سـطح احتمـال

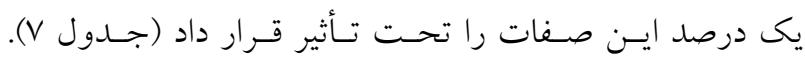
افزايش معنىدار تعداد سنبله در سال دوم در مقايسه با سال اول

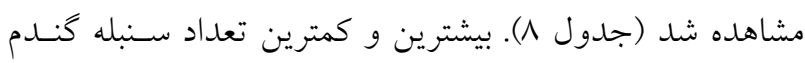

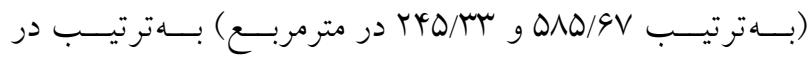

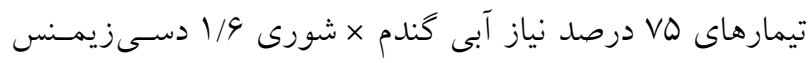

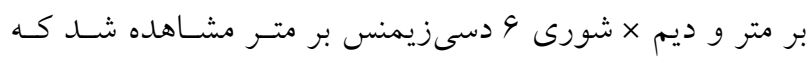

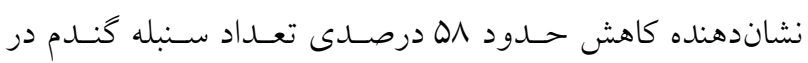


جدول V. ميانگين مربعات اثر خشكى و شورى بر اجزاى عملكرد، عملكرد و شاخص برداشت كندم رقم سيروان

\begin{tabular}{|c|c|c|c|c|c|c|c|}
\hline شرداشت & عملكرد دانه & بيولوزيك عملكرد & وزن هزاردانه & تعر سنبله دانه & تعداد سنبله & آزادى درجه & منبع تغييرات \\
\hline $1 \% / / q^{n s}$ & ryog911/\%** & IVQIYKYAN/** & $\circ / 9)^{\mathrm{ns}}$ & $|40 \circ / 4|^{* *}$ & YAVVG/9 $0^{* *}$ & 1 & سال \\
\hline $9 / 10$ & ITOITN & RTMNNI & $r / 19$ & $r / \Delta \Lambda$ & TVGN/AT & 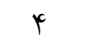 & تكرار × سال \\
\hline ITYN/YY** & 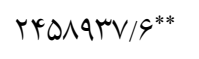 & $1.904190 / 1^{* *}$ & $\mu \psi_{\circ} / 9 q^{* *}$ & $\vee \vee Q / \Delta 0^{* *}$ & ITGKYV/Yo** & $\varphi$ & خشكى \\
\hline $9 \% / 90^{* *}$ & 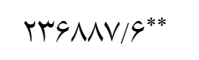 & $\mid r G V Y<4 / 0^{* *}$ & $9 / N \lambda^{\mathrm{ns}}$ & $10 Y / O N^{* *}$ & $Y \circ \circ V / 9 \varphi^{*}$ & $r$ & سال × خشكى \\
\hline $1 V 9 / 00^{* *}$ & 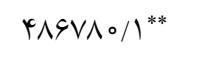 & 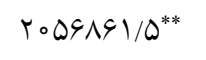 & $\Delta Q^{r} / q^{* * *}$ & $\left.|V G| \Lambda\right|^{* *}$ & $M T V Q / \circ 0^{*}$ & 1 & شورى \\
\hline$\Gamma \Gamma V / \Delta^{* *}$ & $r V \circ 41 / q^{* *}$ & DqYq० 1/०** & $T Q / \uparrow q^{*}$ & $11 / 4 \Lambda^{*}$ & 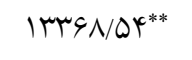 & r & خشكى × شورى \\
\hline $10 \% / r^{* * *}$ & 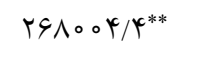 & TEYTNYN/ ** & $10 / 4 \Delta^{\mathrm{ns}}$ & $r r / N Q^{n s}$ & $\Delta K Y \Lambda 1 / 0 q^{* *}$ & 1 & سال × شورى \\
\hline$\circ / V r^{* *}$ & $41991 / N^{* *}$ & $Y \Lambda T V \circ \Lambda / Q^{* *}$ & $I T / V \lambda^{\mathrm{ns}}$ & r/9 $q^{\mathrm{ns}}$ & $\mid r \circ Y \Delta N / 10^{* *}$ & r & سال × خشكى × شورى \\
\hline$r \circ N / D Q$ & $919 V / 4$ & $r \circ V Q N / \Delta$ & $9 / 90$ & $\mu / \mu_{0}$ & $\mid r Q H / G Y$ & rq & خطاى آزمايشى \\
\hline $9 / 11$ & $V / q_{0}$ & $9 / \pi 9$ & $V / 09$ & $9 / 99$ & $\Lambda / I V$ & -- & ضريب تغييرات (\%) \\
\hline
\end{tabular}

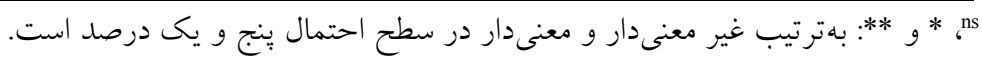

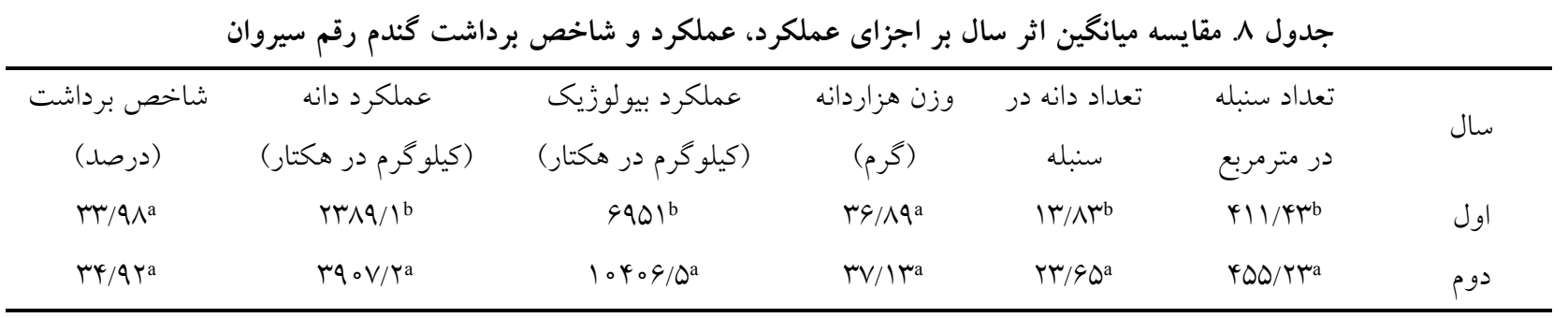

ميانكينهاى هر ستون كه داراى حداقل يك حرف مشترك هستند، بر اساس آزمون LSD اختلاف معنى دارى در سطح ينج درصد ندارند.

جدول 9. مقايسه ميانگين اثر خشكى و شورى بر اجزاى عملكرد، عملكرد و شاخص برداشت گندم رقم سيروان

\begin{tabular}{|c|c|c|c|c|c|c|c|}
\hline شاخص برداشت & عملكرد دانه & عملكرد بيولوزيك & وزن هزاردانه & & تعداد سنبله & \multicolumn{2}{|c|}{ تيمار } \\
\hline$Y N / G Y^{a}$ & $M G Y D / I^{\circ}$ & $V G \circ \wedge / \mu^{c}$ & $r_{\Lambda / T \mu \mathrm{rbc}}$ & $r Y / \Lambda r^{\mathrm{ab}}$ & rVY/TYc & عدم شورى & آساري همه \\
\hline$r y / l V^{c}$ & $r V V I / q^{d}$ & $\Lambda \circ \mu r / \mu^{c}$ & rq/. Y & $19 / 99 \mathrm{~cd}$ & $r \times q / I V^{b}$ & شورى & \\
\hline$r N / q V^{b}$ & $r_{\Lambda \Delta Q / q^{\circ}}$ & $9900 / 0^{b}$ & $r q / \Delta r^{\mathrm{ab}}$ & $\Gamma Y^{\prime} / \Lambda \Gamma^{\mathrm{\mu}}$ & $\Delta \wedge \Delta / 9 \vee^{\mathrm{a}}$ & عدم شورى & \\
\hline $\mathrm{rV} / \mathrm{N} \mathrm{cbc}^{\mathrm{bb}}$ & TGYN/GC & $৭ 9 \Delta \wedge / \Gamma^{\mathrm{b}}$ & $\Gamma_{N} / \Delta \Delta^{b c}$ & $\mid N / \Lambda \mu^{d}$ & $Y \wedge 1 / 0 \circ b$ & شورى & ابيارى ما \\
\hline$r y / Q \mu^{c}$ & rrqa/vab & $\mid r \circ \circ \Delta / o^{a}$ & $|4| / T^{a b}$ & $r Y / \mid \varphi^{a b}$ & $Y V Y / I V^{b}$ & عدم شورى & آسارى ه ه 1 \\
\hline$r q / r q^{b}$ & $r_{\Lambda \circ} \psi^{\prime} / N^{c}$ & $9999 / \mathrm{N}^{\mathrm{b}}$ & $r q / T Y^{a b}$ & $Y Y / \Delta_{0} \mathrm{bc}$ & $\kappa \wedge \Delta / \Lambda r^{b}$ & شورى & ابيزلى فا \\
\hline rG/KYbc & $x<q_{0} / x^{a}$ & IYYVQ/ $\mathrm{oa}^{\mathrm{a}}$ & $Y Y / / l^{a}$ & $r r / Q_{0} a b$ & $19 \% / \circ 0^{b}$ & عدم شورى & آبيارى Tro \\
\hline$r \mathrm{~V} / / q^{\mathrm{bc}}$ & $r \Delta \wedge q / \psi^{\circ}$ & $990 / / / r^{\mathrm{b}}$ & $Y / N V^{a}$ & $19 / 19^{\mathrm{d}}$ & $r q V / T^{b}$ & شورى & \\
\hline $\mid N / V \psi^{\alpha d}$ & $\Lambda \circ \psi / \Delta^{e}$ & 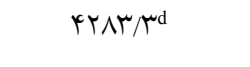 & YN/DGd & $9 / 00^{e}$ & $Y \wedge Y / 00^{d}$ & عدم شورى & נد \\
\hline $\mid Q / T \Lambda^{\mathrm{d}}$ & OTO/Ve & $r Y Q 0 / 0^{e}$ & $r Y / 9 q e$ & $9 / 00^{f}$ & $r Y \Delta / M \Gamma^{d}$ & 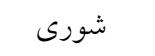 & r \\
\hline
\end{tabular}

ميانكينهاى هر ستون كه داراى حداقل يكى حرف مشترى هستند، بر اساس آزمون LSD اختلاف معنى ارىى در سطح بنج درصد ندارند. 
شورى قرارگرفته و برهم كنش دو عامل خشكى و شورى نيز در

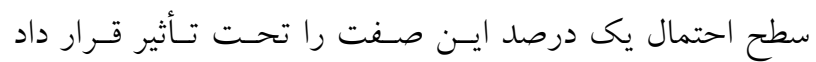

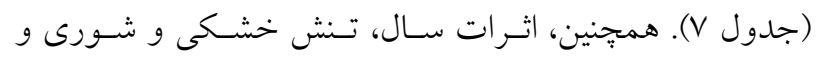

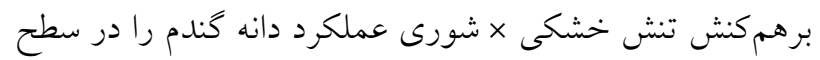

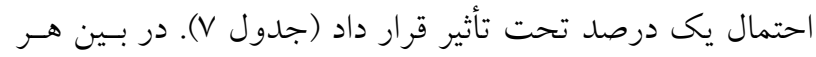

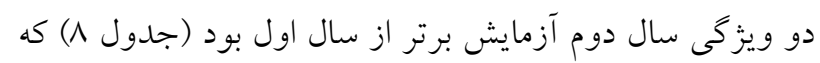

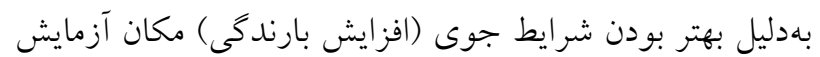

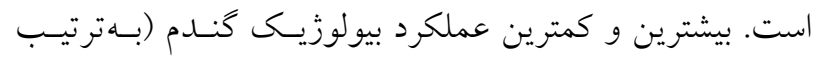

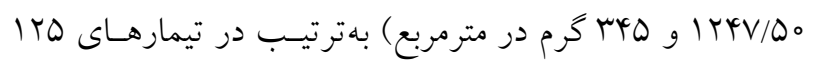

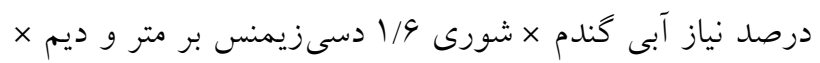

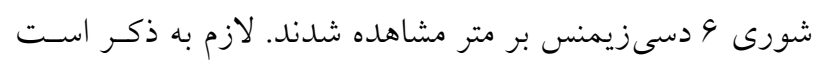

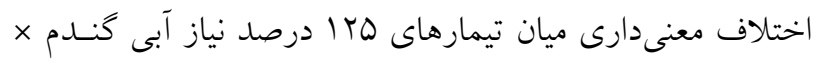

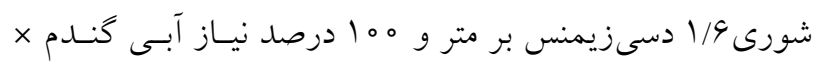

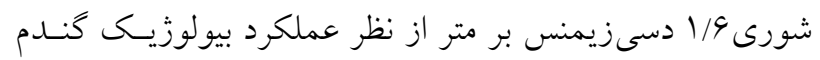

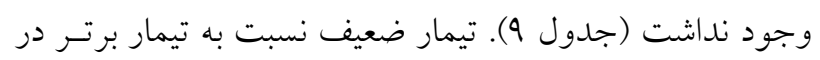

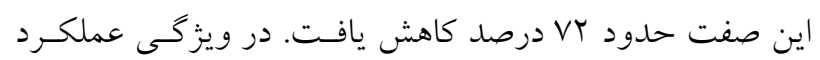

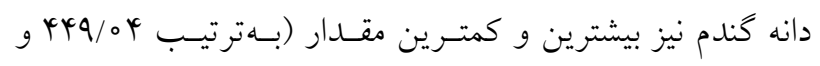
ITQ IT ST/OV

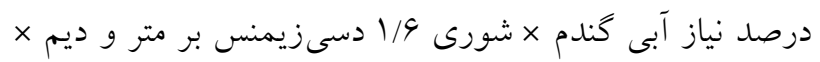

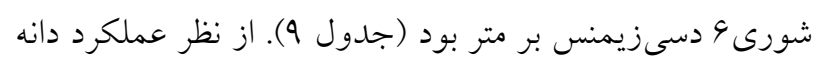

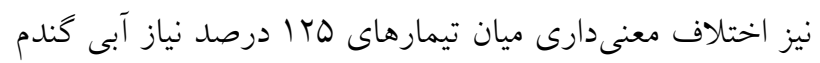

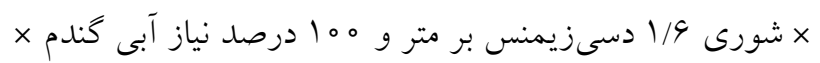
شورى // ادسىزيمنس بر متر وجود نداشت. افت عملكرد دانه

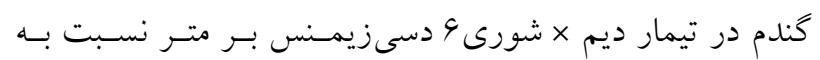

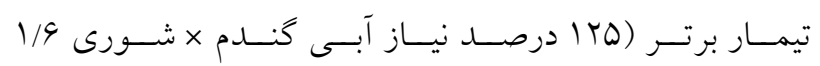
دسىزيمنس بر متر) حدود M درصد بود.

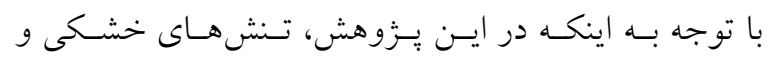

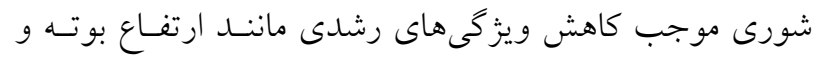
وزن برى بوتها و نيز اجزاى عملكرد شامل تعداد سنبله، تعداد دانه و وزن دانهها شد لذا كاهش عملكردهاى بيولوزيك و دانسه

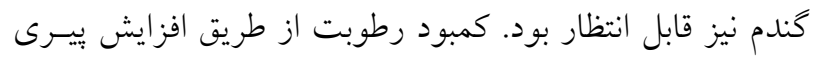

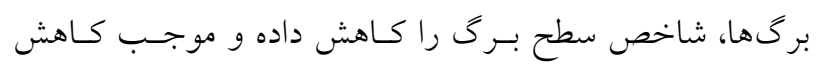

در سال MM Ir در تحقيقى روى اثر تنش خشكى بـر عملكــد و

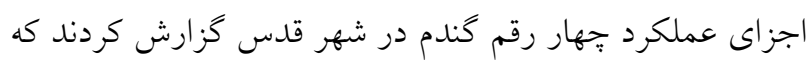

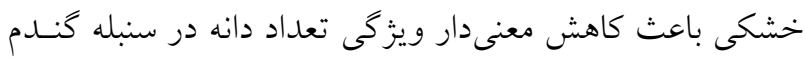

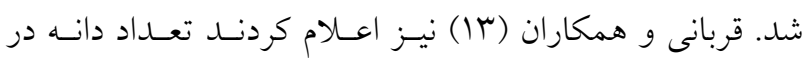
كُندم، تحت تأثير تنش شورى كاهش مى يابد.

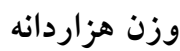

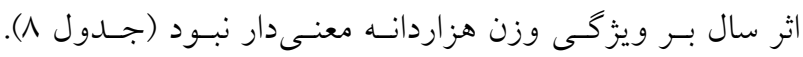

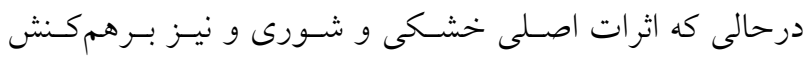

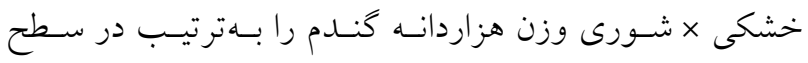

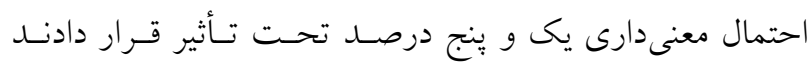

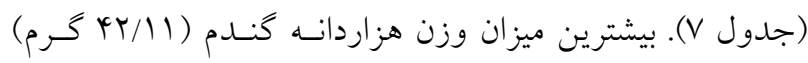

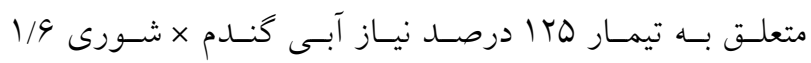

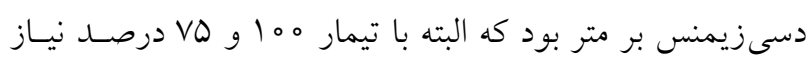

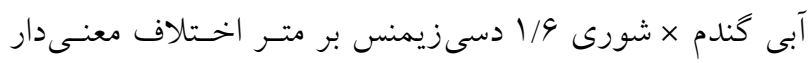

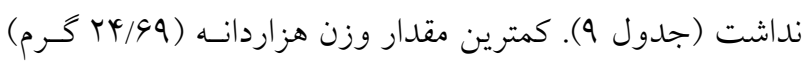

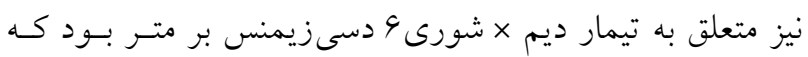

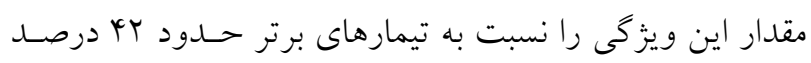

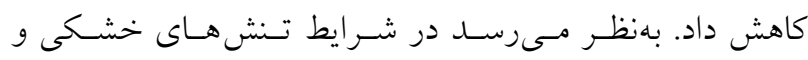

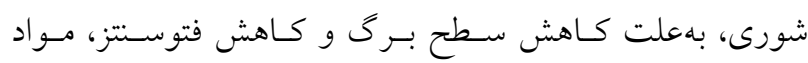

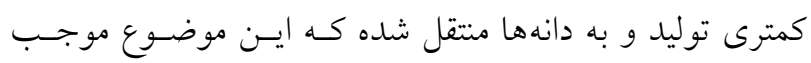
كاهش وزن دانهها شد. از سوى ديخر در اثر خشكى، طول دوره

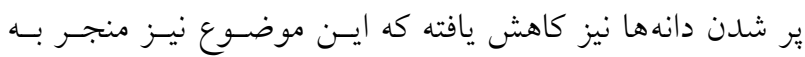

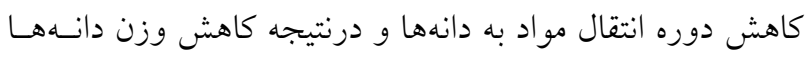

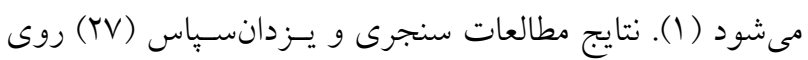

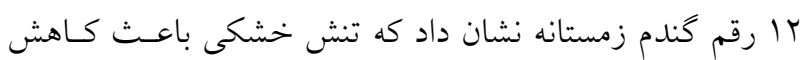

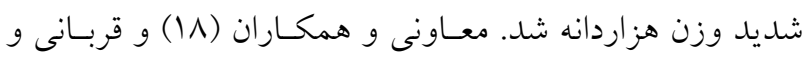

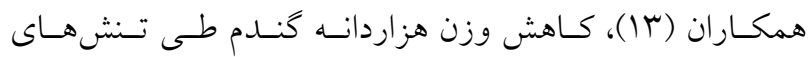
خشكى و شورى را گزارش كردهاند.

\section{عملكرد بيولوزيك و دانه}

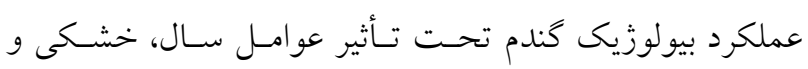




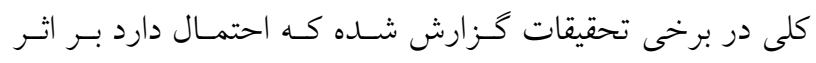

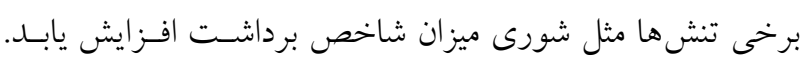

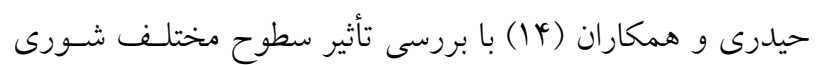

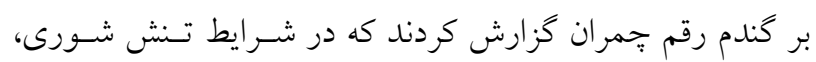

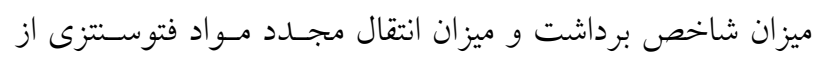

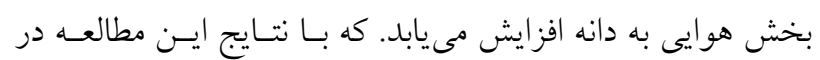

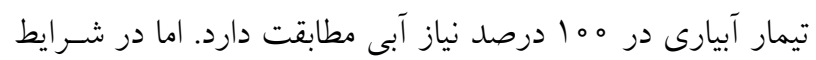

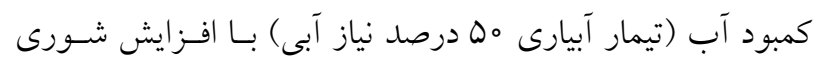
آب ميزان شاخص برداشت كاهش معنى دارى را نشان داد.

\section{نتيجه گيرى}

نتايج مطالعه حاضر نشان داد كه بيشتر صفات رشدى و عملكرد

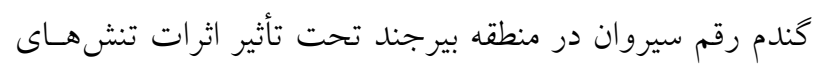
خشكى و شورى و برهم كنش خشكى × شـورى قـرار كرفـت دئ.

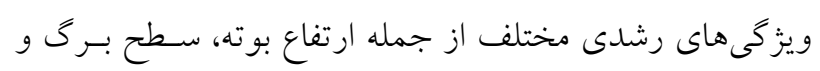

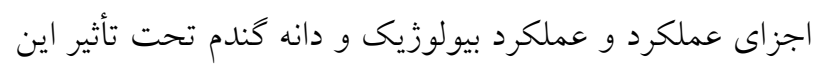

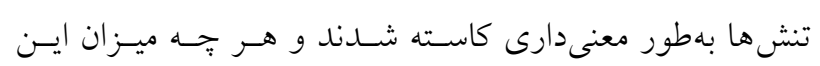
تنشها افزايش يافت، كاهش اين ويزگكى ها بيشتر شد. بـا توجـهـ

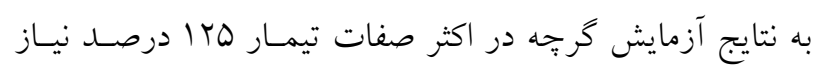

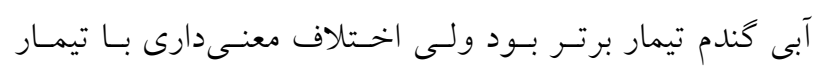

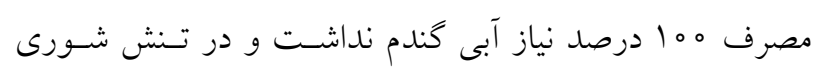

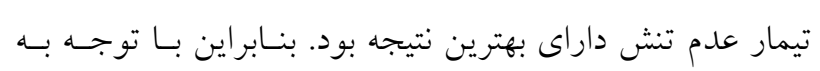
بروز و يبشبينى خشكسالى در كشور، توصيه مىشود از اعمـال

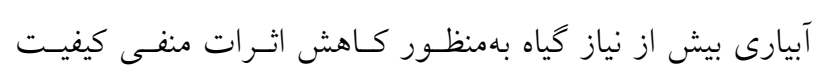
نامطلوب آب خوددارى شود.

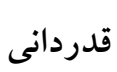

نويسندكان از همكارى صميمانه جناب آقاى مهندس صمد زاده

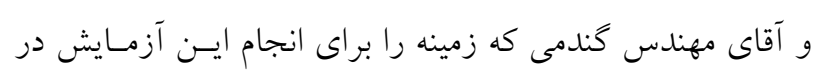

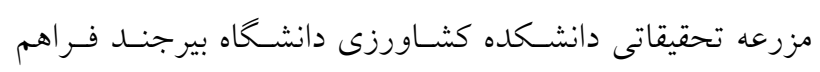
كردند كمال تقدير و تشكر را دارند.
توليد فراوردههاى فتوسنتزى و عملكرد بيولوزيك مسى شـود (r)

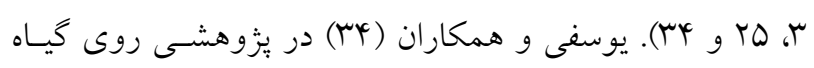

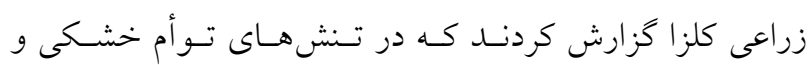

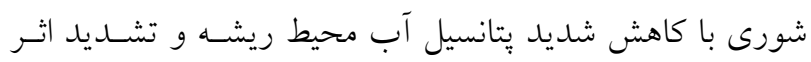

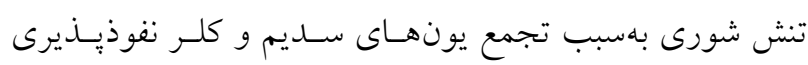

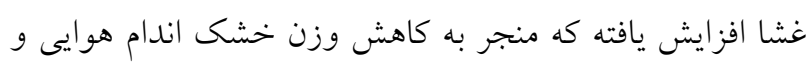

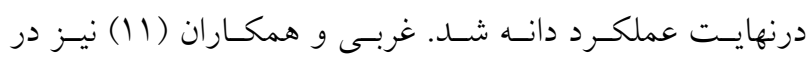
بررسى ارزيابى تحمل به تنش شورى و خشكى لاينهاى كنــدم

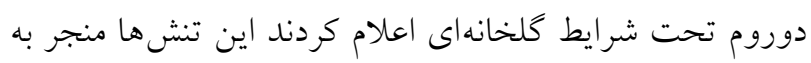
كاهش اجزاى عملكرد و عملكرد دانه و بيولوزيك كندم شــنداند.

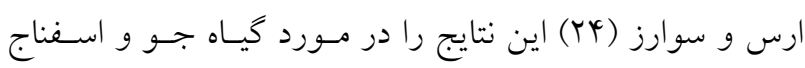

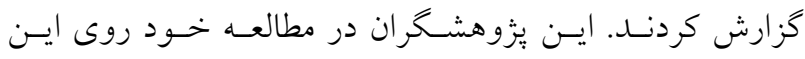

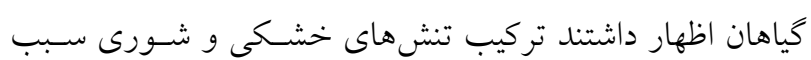

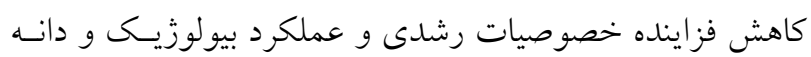
اين گياهان شد. شاخص برداشت

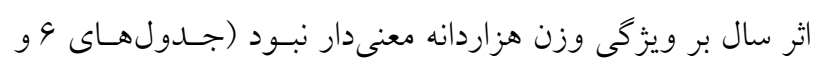

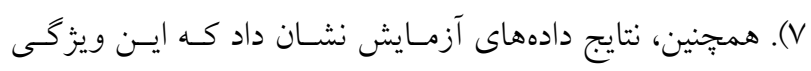

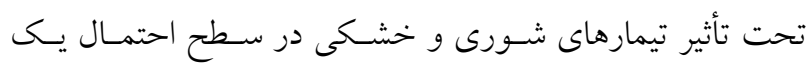

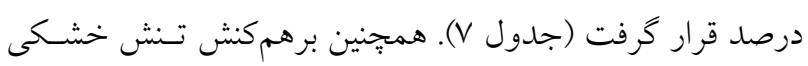

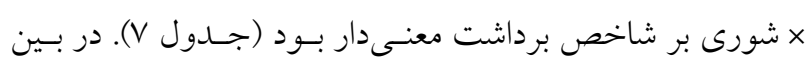

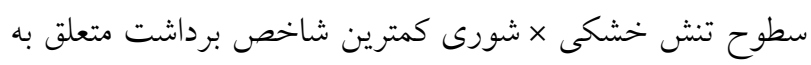

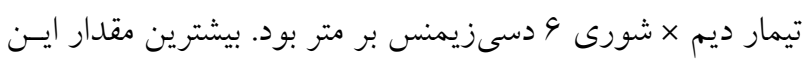

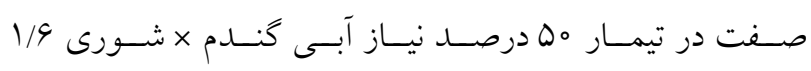

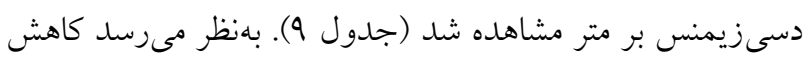

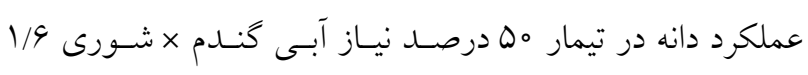

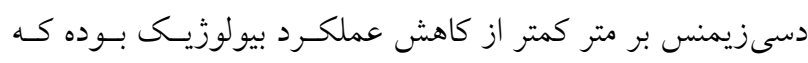

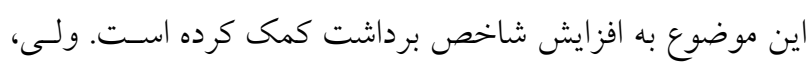

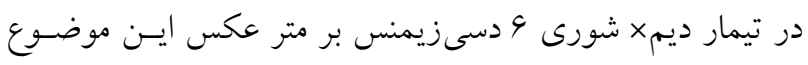

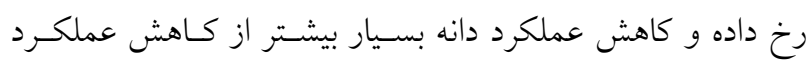
بيولوزيك بوده و درنتيجه شاخص برداشت كم شده است. بهطور 
1. Ahmed, I., U. Nadira, N. Bibi, G. P. Zhang and F. Wu. 2015. Combined Stresses in Forests. In: Mahalingham, R. (Ed). Combined Stresses in Plants. Physiological, Molecular and Biochemical Aspects. Springer.

2. Asgari, H. R., W. Cornelis and P. Van Damme. 2011. Effect of salinity on wheat (Triticum aestivum L.) grain yield, yield components and ion uptake. Desert 16: 169-175.

3. Cakir, R. 2004. Effect of water stress at different development stages on vegetative and reproductive growth of corn. Field Crops Research 89: 1-16.

4. El-Hendawy, S. E., Y. Hu, G. M. Yakout, A. M. Awad, S. E. Hafiz and U. Schmidhalter. 2005. Evaluating salt tolerance of wheat genotypes using multiple parameters. European Journal of Agronomy 22: 243-253.

5. Eydizadeh, K. H., F. Ebrahimpour and M. Ebrahimi. 2016. Effect of different irrigation Regimes on yield and yield components of wheat cultivars in Ramin climatic conditions. Journal of Environmental Stresses in Crop Sciences 9: 36-29. (In Farsi).

6. Fang, Y., Y. Du, J. Wang, A. Wu, S. Qiao, B. Xu, S. Zhang, K. H. M. Siddique and Y. Chen. 2017. Moderate drought stress affected root growth and grain yield in old, modern and newly released cultivars of winter wheat. Frontiers in Plant Science 8: 672.

7. FAOSTAT AGRICULTURE DATA. 2017. Available at: http://faostat3.fao.org.

8. Farooq, M., M. Hussain, A. Wakeel and K. H. Siddique. 2015. Salt stress in maize: effects, resistance mechanisms, and management. A review. Agronomy for Sustainable Development 35: 461-481.

9. Farooq, M., M. Irfan, T. Aziz, I. Ahmad and S. A. Cheema. 2013. Seed priming with ascorbic acid improves drought resistance of wheat. Journal of Agronomy and Crop Science 199: 12-22.

10. Farooq, M. A., N. Wahid, D. F. Kobayashi and S. M. A. Basra. 2009. Plant drought stress: effects, mechanisms and management. Agronomy for Sustainable Development 29: 185-212.

11. Gharbi, A., V. Rashidi, A. R. Tarinejad and S. ChalabiYani. 2014. Evaluation of durum wheat lines tolerance to salinity and drought stress under greenhouse conditions. Journal of Crop Ecophysiology 7: 393-410. (In Farsi).

12. Ghavam Saeidi Noghbi, S., M. Yaghoobzadeh, A. Shahidi and H. Hammami. 2020. Interaction effects of different irrigation levels and water salinity on growth, yield and yield components of wheat (Triticum aestivum L.) in Birjand region. Environmental Stresses in Crop Sciences 13: 211-223. (In Farsi).

13. Ghorbani, M. H., E. Zeinali, A. Soltani and S. Galeshi. 2004. The effect of salinity on growth, yield and yield component in two wheat cultivars. Journal of Agricultural Sciences and Natural Resources 10: 5-13. (In Farsi).

14. Heidari, M., A. M. Bakhshandeh, H. Nadidan, G. Fathi and K. H. Alemisaid. 2006. Effects of salinity and nitrogen rates on grain yield, osmotic adjustments, sodium and potassium uptake in wheat cultivar chamran. Iranian Journal of Agriculture Sciences 37: 501-513. (In Farsi).

15. Houshmand, S., A. Arzani and S. A. M. Mirmohammadi-Maibody. 2014. Effects of salinity and drought stress on grain quality of durum wheat. Communications in Soil Science and Plant Analysis 45: 297-308.

16. Karimi, M. 2020. Wheat (Bam variety) responses to interactive effects of irrigation water salinity and different rates of potassium sulphate fertilizer. Environmental Stresses in Crop Sciences 12: 239-129. (In Farsi).

17. Mashi, A., S. Galeshi, E. Zeinali and A. Noorinia. 2007. Salinity effect on seed yield and yield components in four hull-les barley. Journal of Agriculture Science and Natural Resources, Special Issue, Agromony and Plant Breeding 14: 86-98. (In Farsi).

18. Moaveni, P., D. Habibi and B. Abbaszadeh. 2009. Effect of drought stress on yield and yield components of four wheat cultivars in shahr-e-gods. Agronomy and Plant Breeding 5: 69-85. (In Farsi).

19. Mohajer milani, P., S. Saadat and R. Vakil. 2000. Nutrition of wheat in the conditions of qom province. Collected Articles of Balanced Wheat Feed 429-444. (In Farsi).

20. Mosaffa, H. R. and A. R. Sepaskhah. 2019. Performance of irrigation regimes and water salinity on winter wheat as influenced by planting methods. Agricultural Water Management 216: 444-456.

21. Nabizadeh Marvdust, M. R., M. Kafi and M. H. Rashed Mohasel. 2003. Effect of salinity on growth, yield, collection of minerals and percentage of green cumin essence. Journal of Iran Arable Studies 1: 53-59. (In Farsi).

22. Najafian, G., M. Rahmati, A. Amini, F. Afshari, A. Malihipour and G. Ahmadi. 2012. Sirvan, new wheat cultivar, enduring seasonal drought and good quality bakeries for cultivation in irrigated fields of Iran. Research Achievements for Field and Horticulture Crops 1: 1-10. (In Farsi).

23. Naureen, G. and F. N. Naqvi. 2010. Salt tolerance classification in wheat genotypes using reducing sugar accumulation and growth characteristics. Emirates Journal of Food and Agriculture 308-317.

24. Ors, S. and D. Suarez. 2017. Spinach biomass yield and physiological response to interactive salinity and water stress. Agricultural Water Management 190: 31-41.

25. Rajaie, M., S. Tahmasebi, M. J. Bidadi, K. Zare and S. Sarfarazi. 2016. The effect of terminal drought stress on yield and yield components of wheat genotypes. Cereal Research 5: 341-352. (In Farsi). 
26. Sadat Noori, S. S., A. Roustaei and B. Foghi. 2006. Variability of salt tolerance for eleven traits in bread wheat grown in different saline conditions. Journal of Agronomy 5: 131-136. (In Farsi).

27. Sanjari, P. A. and A. Yazdansepas. 2008. Mobilization of Dry Matter and Its Relation with Drought Stress in Wheat Genotypes. Journal of Agricultural Science and Technology 11: 121-129.

28. Sedaghat, M., Z. Tahmasebi-Sarvestani, Y. Emam and A. Mokhtassi-Bidgoli. 2017. Physiological and antioxidant responses of winter wheat cultivars to strigolactone and salicylic acid in drought. Plant Physiology and Biochemistry 119: 59-69.

29. Shahidi, A. and Z. Miri. 2018. The Effect of salinity on yield and yield components of two wheat cultivars in the plain of birjand. Crop Production 11: 51-61.

30. Shirinbayan, S., H. Khosravi and M. J. Malakouti. 2019. Alleviation of drought stress in maize (Zea mays) by inoculation with azotobacter strains isolated from semi-arid regions. Applied Soil Ecology 133: 138-145.

31. Tavousi, M., F. Kaveh, A. Alizadeh, H. Babazadeh and A. Tehranifar. 2015. Effects of drought and salinity on yield and water use efficiency in pomegranate tree. Journal of Materials and Environmental Science 6: 1975-1980.

32. Zamani, Z., H. Kashkoli, A. Shahidi and G. H. Qureshi. 2007. Effects of salinity and different irrigation regimes on yield, yield components and grain protein percentage in wheat cultivars. First Conference on Adaptation to Dehydration, Tehran Monthly Mehr Ab. (In Farsi).

33. Zhang, J., S. Zhang, M. Cheng and J. Jin. 2018. Effect of drought on agronomic traits of rice and wheat: A metaanalysis. Journal of Environmental Research and Public Health 15: 839-853.

34. Yousefi, F., P. Hassibi, H. Roshanfekr and M. Meskarbashee. 2016. Study of drought and salinity stress effect on some physiological characters of two canola (Brassica napus L.) varieties in Ahvaz. Journal of Plant Production 38: 25-34. (In Farsi). 


\title{
The Effect of Deficit Irrigation and Saline Water Treatments on Growth and Yield Responses of Sirvan Bread Wheat Cultivar
}

\author{
F. Hajiabadi', 5, F. Hassanpour ${ }^{2}$, M. Yaghoobzadeh ${ }^{3}$, H. Hammami ${ }^{*}$ \\ and S. M. Seyyedi ${ }^{6}$
}

(Received: June 10-2020; Accepted: November 08-2020)

\begin{abstract}
Today, maintaining the quantity and quality of irrigation water are the most critical challenges in the agriculture system, especially in arid and semi-arid regions of the world. Accordingly, to evaluate the growth and yield responses of bread wheat (Sirvan cultivar) to different levels of deficit irrigation and water salinity, a factorial experiment was conducted in a randomized complete block design with three replications in the Research Field of Agriculture Faculty of the University of Birjand, at Birjand (east of Iran) during the growing seasons of 2016-2017 and 2017-2018. The experimental treatments included irrigation at five levels $(125,100,75$, and 50\% of wheat water requirement and rainfed with two supplementary irrigation at the first growing season) and saline water at two levels $(1.6 \mathrm{dS} / \mathrm{m}$ and $6 \mathrm{dS} / \mathrm{m})$. The results showed that growth characteristics, yield components, biological yield, and grain yield were affected by deficit irrigation water and saline water. These treatments significantly reduced all of the measured traits. The lowest leaf area was observed in rain-fed with $6 \mathrm{dS} / \mathrm{m}$ saline water treatment, which suppressed this trait by $61 \%$ compared to $125 \%$ water requirement with $1.6 \mathrm{dS} / \mathrm{m}$ saline water treatment. The highest and the lowest biological yield and grain yield were observed in $125 \%$ water requirement with $1.6 \mathrm{dS} / \mathrm{m}$ saline water and rain-fed with $6 \mathrm{dS} / \mathrm{m}$ saline water treatments, respectively. Non-significant differences were observed in biological and grain yield between $125 \%$ water requirement with $1.6 \mathrm{dS} / \mathrm{m}$ saline water and $100 \%$ water requirement with $1.6 \mathrm{dS} / \mathrm{m}$ saline water treatments. Biological yield and grain yield were decreased in rain-fed with $6 \mathrm{dS} / \mathrm{m}$ saline water treatment compared to $125 \%$ water requirement with $1.6 \mathrm{dS} / \mathrm{m}$ salinity treatment by $72 \%$ and $88 \%$, respectively. Results of this study showed that although the greatest amounts of yield attributes were obtained upon using the $125 \%$ water requirement treatment, but these attributes were not significantly greater than the $100 \%$ water requirement treatment. Consequently, in areas with scarce water and saline water $(6 \mathrm{dS} / \mathrm{m})$, reliance on the $75 \%$ water requirement with $6 \mathrm{dS} / \mathrm{m}$ saline water and $100 \%$ water requirement with $1.6 \mathrm{dS} / \mathrm{m}$ saline water treatments may suffice to achieve an acceptable grain yield and to save water under saline water condition.
\end{abstract}

Keywords: Biological yield, Grain yield, Saline water

1, 2. PhD Graduate and Associate Professor, Respectively, Department of Water Engineering, College of Water and Soil, University of Zabol, Zabol, Iran.

3, 4, 5. Associate Professor, Department of Water Engineering, Assistant Professor of Department of Agronomy, and Laboratory Instructor of Department of Water Science and Engineering, Respectively, College of Agriculture, University of Birjand, Birjand, Iran.

6. Researcher, Research Department of Markazi Province's Agricultural Research and Education Center (AREEO), Arak, Iran.

*: Corresponding Author, Email: hhammami@birjand.ac.ir 